\title{
Sex-Specific Role for Dopamine Receptor D2 in Dorsal Raphe Serotonergic Neuron Modulation of Defensive Acoustic Startle and Dominance Behavior
}

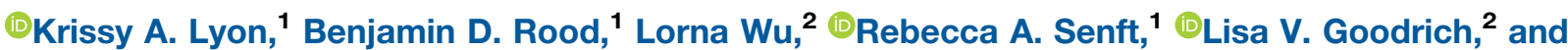 \\ DSusan M. Dymecki ${ }^{1}$
}

https://doi.org/10.1523/ENEURO.0202-20.2020

${ }^{1}$ Department of Genetics, Harvard Medical School, Boston, MA 02115 and ${ }^{2}$ Department of Neurobiology, Harvard Medical School, Boston, MA 02115

\section{Visual Abstract}
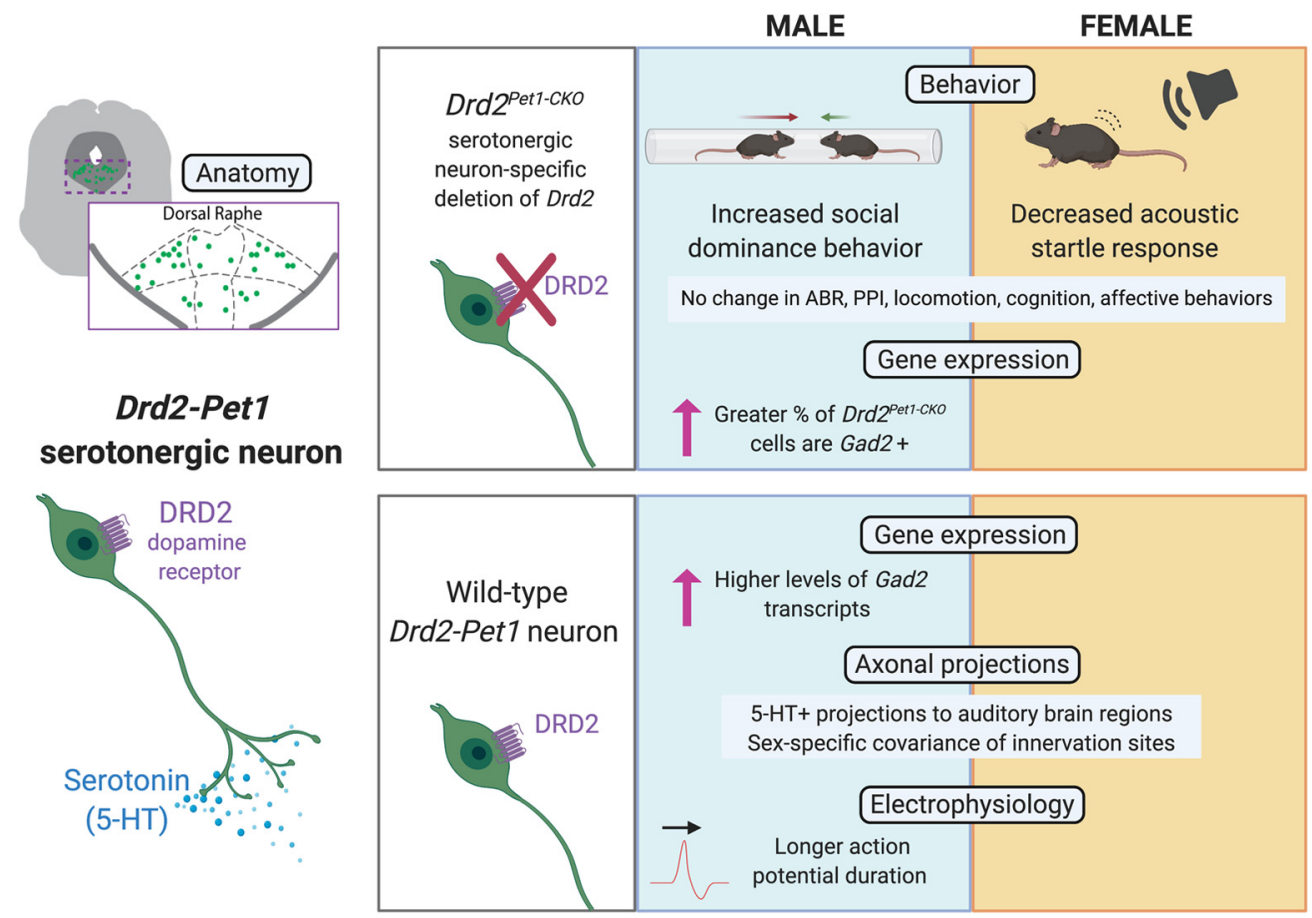

Brain networks underlying states of social and sensory alertness are normally adaptive, influenced by serotonin and dopamine (DA), and abnormal in neuropsychiatric disorders, often with sex-specific manifestations. Underlying circuits, cells, and molecules are just beginning to be delineated. Implicated is a subtype of serotonergic neuron denoted Drd2-Pet1, distinguished by expression of the type-2 DA receptor (Drd2) gene, inhibited cell-autonomously by DRD2 agonism in slice, and, when constitutively silenced in male mice, affects levels of defensive and exploratory behaviors (Niederkofler et al., 2016). Unknown has been whether DRD2 signaling in these Pet1 neurons contributes to their capacity for shaping defensive behaviors. To address this, we generated mice in which Drd2 gene sequences were deleted selectively in Pet1 neurons. We found that $D r d 2^{\text {Pet1-CKO }}$ males, but not females, demonstrated increased winning against sex-matched controls in a social 


\section{Significance Statement}

A subtype of dorsal raphe (DR) serotonergic neuron, denoted Drd2-Pet1, is poised for regulation by dopamine (DA) via type-2 DA receptor (DRD2) expression. Functional removal of DRD2 in these cells through a conditional knockout (CKO) mouse strategy resulted in sex-specific behavioral abnormalities: Drd2 ${ }^{\text {Pet1-CKO }}$ females exhibited reduced acoustic startle while males showed increased social dominance. Drd2-Pet1 neurons were similar in number and distribution in males versus females but exhibited sex-specific differences in neurotransmission-related mRNAs, action potential (AP) duration, and relative distribution of collaterals. Abnormalities in sensory processing and social behaviors akin to those reported here manifest in autism, schizophrenia, and posttraumatic stress disorder, in sex-specific ways. Our findings, thus, may point to novel circuits and modulatory pathways relevant to human neuropsychiatric conditions.

dominance assay. Drd2 $2^{P e t 1-C K O}$ females, but not males, exhibited blunting of the acoustic startle response, a protective, defensive reflex. Indistinguishable from controls were auditory brainstem responses (ABRs), locomotion, cognition, and anxiety-like and depression-like behaviors. Analyzing wild-type Drd2-Pet1 neurons, we found sex-specific differences in the proportional distribution of axonal collaterals, in action potential (AP) duration, and in transcript levels of Gad2, important for GABA synthesis. Drd2 $2^{\text {Pet1-CKO }}$ cells displayed sex-specific differences in the percentage of cells harboring Gad2 transcripts. Our results suggest that DRD2 function in Drd2-Pet1 neurons is required for normal defensive/protective behaviors in a sex-specific manner, which may be influenced by the identified sex-specific molecular and cellular features. Related behaviors in humans too show sex differences, suggesting translational relevance.

Key words: acoustic startle; dominance; dopamine receptor; raphe; serotonin; sex differences

\section{Introduction}

The serotonergic and dopaminergic neurotransmitter systems are known for their influence on and maladaptation in neuropsychiatric disorders, including posttraumatic stress disorder, autism spectrum disorder, and

Received May 19, 2020; accepted November 9, 2020; First published December 19, 2020.

The authors declare no competing financial interests.

Author contributions: K.A.L. and S.M.D. designed research; K.A.L., B.D.R., and L.W. performed research; R.A.S. and L.V.G. contributed unpublished reagents/analytic tools; K.A.L., B.D.R., R.A.S., L.V.G., and S.M.D. analyzed data; K.A.L. and S.M.D. wrote the paper.

This work was supported by the National Institutes of Health National Institute on Drug Abuse Grant R01 DA034022 (to S.M.D.) and Blueprint Award NS108515 (to K.A.L.), the National Institute on Deafness and Other Communication Grant R01 DC015974 (to L.V.G.), and G.V.R. Khodadad Fund for studies of EPS (S.M. D.). K.A.L. was a Howard Hughes Medical Institute Gilliam Fellow.

B. D. Rood's present address: Department of Cell Biology and Neuroscience, Rowan University, Stratford, NJ 08084.

Acknowledgements: We thank all S.M.D. laboratory members, including G. Maddaloni, B. Okaty, R. Dosumu-Johnson, K. Lehigh, and T. Asher, for discussions; O. Alekseyenko for discussion and behavioral assay support; K. Blandino, B. Menjivar, M. Rice, and J. Mai for technical support; B. Shrestha for auditory brainstem response assistance; and the Microscopy Resources on the North Quad (MicRoN) core at Harvard Medical School for microscopy support. Graphical abstract and tube test diagram created with BioRender. com. Most behavioral work was carried out in the NeuroBehavior Laboratory Core at Harvard Medical School, we thank the support of Director Dr. Barbara Caldarone.

Correspondence should be addressed to Susan M. Dymecki at dymecki@ genetics.med.harvard.edu.

https://doi.org/10.1523/ENEURO.0202-20.2020

Copyright (C) 2020 Lyon et al.

This is an open-access article distributed under the terms of the Creative Commons Attribution 4.0 International license, which permits unrestricted use, distribution and reproduction in any medium provided that the original work is properly attributed. schizophrenia. Clinical and animal studies implicate serotonin (5-hydroxytryptamine; 5-HT) and dopamine (DA) in modulation of endophenotypes common to neuropsychiatric disorders, such as altered social interaction and sensory processing (Geyer and Braff, 1987; Meincke et al., 2004; Takahashi and Kamio, 2018). Transcriptome data coupled with structure-function maps in mice show that the serotonergic and dopaminergic neuronal systems are themselves heterogeneous, comprised of functionally specialized neuronal subtypes, manifesting distinct mRNA profiles, efferent projections, electrophysiological properties, and functions (Jensen et al., 2008; Kim et al., 2009; Crawford et al., 2013; Lammel et al., 2014; Spaethling et al., 2014; Okaty et al., 2015; Deneris and Gaspar, 2018; Poulin et al., 2018, 2020; Huang et al., 2019; Ren et al., 2019; Okaty et al., 2020). An important subtype of serotonergic neuron as relates to social and defensive behaviors is denoted Drd2-Pet1 (Niederkofler et al., 2016), identified by expression of the type-2 DA receptor (Drd2) gene and the serotonergic transcription factor gene Pet1 (aka Fev). DRD2 agonism in slice preparation drove outward (inhibitory) currents cell-autonomously in Drd2-Pet1 neurons, suppressing their excitability; and when these cells were constitutively silenced in male mice, i.e., exocytic neurotransmitter release was cell autonomously blocked, defensive, aggressive, and exploratory behaviors increased (Niederkofler et al., 2016). Here, we query whether Drd2 expression in Drd2-Pet1 cells contributes to the modulation of defensive, exploratory behaviors.

While Drd2 is expressed in many cell types throughout the midbrain and basal forebrain, expression in serotonergic neurons is restricted to a small subset of cells resident in the dorsal raphe (DR) nucleus. In these serotonergic neurons, Drd2 expression initiates around adolescence 
and continues through adulthood, at which point, Drd2 transcripts are the major DA receptor mRNA detected (Niederkofler et al., 2016). Thus, Drd2-Pet1 neurons come under DRD2 and presumably DA regulation during the developmental transition to sexual maturity. Drd2-Pet1 neurons project to brain regions involved in sensory processing, defensive, and mating behaviors including auditory brainstem regions and the sexually dimorphic medial preoptic area (mPOA; Niederkofler et al., 2016). These findings led us to hypothesize that DRD2 signaling in Drd2-Pet1 neurons contributes to social and sensory alertness and defensive behavior in a sex-specific manner.

Indeed, serotonergic and dopaminergic perturbations affect social and defensive behaviors differently in male versus female rodents. Decreases in serotonergic tone associate with increased levels of aggression in males (Brown et al., 1982; Hendricks et al., 2003; Yu et al., 2014; Niederkofler et al., 2016). By contrast, lesions of the serotonergic DR in female rats decreased maternal aggression (Holschbach et al., 2018), while DR serotonergic neuron activity in female, but not male, hamsters associates with social dominance (Terranova et al., 2016). The acoustic startle reflex (ASR), an evolutionarily-conserved, defensive reflex to loud, potentially threatening stimuli (Davis et al., 1982), also shows sex-specific differences within the context of altered 5-HT levels. Reduction in 5-HT levels enhanced ASR in female but not male rats (Pettersson et al., 2016). With respect to DA, deletion of the DA re-uptake transporter gene (Dat) altered ASR only in male mice (Ralph et al., 2001). Genetic removal of the soluble form of catechol-O-methyltransferase (COMT), important for degradation of DA, enhanced the ASR and dominance behaviors in both sexes, but ASR especially in males (Tammimäki et al., 2010). Thus, serotonergic and dopaminergic neuronal systems influence social behaviors and sensory processing in sex-specific ways.

Here, we queried whether Drd2 conditional deletion in serotonergic neurons would alter aggression and social dominance behavior in males. Further, we sought to examine the role of Drd2 expression in serotonergic neurons in females with the hypothesis that other sensory or defensive behaviors would be affected, given typical lack of aggression in female mice (Lonstein and Gammie, 2002). We undertook a phenotypic analysis of mice in which we engineered Drd2 gene deletion selectively in ePet1-creexpressing serotonergic neurons ( $\mathrm{Drd} 2^{\text {Pet1-CKO }}$ mice). Here, we report that Drd2 ${ }^{\text {Pet1-CKO }}$ males exhibited increased social dominance whereas females displayed a robust decrease in ASR. We also investigated sex differences in Drd2-Pet1 neurons at the molecular, cellular, and circuit levels, identifying differences in candidate mRNA levels, electrophysiological properties, and relative distribution densities of axonal collaterals.

\section{Materials and Methods}

\section{Ethical approval}

All experimental protocols were approved by Harvard University Institutional Animal Care and Use Committees (IACUC) and were in accordance with the animal care guidelines of the National Institutes of Health.

\section{Experimental animals}

Mice were housed in a temperature-controlled environment on a 12/12 h light/dark cycle with ad libitum access to standard mouse chow and water. All experimental animals were virgins. For conditional knockout of Drd2, double transgenic mice of the genotype ePet-Cre; $\mathrm{Drd} 2^{\text {loxP/loxP }}$ (referred to as $\mathrm{Drd} 2^{\text {Pet1-CKO}}$ ) were generated by crossing BAC transgenic ePet-Cre (Scott et al., 2005; Jax \#012712) males to homozygous Drd2 ${ }^{\text {loxPlloxP }}$ (Bello et al., 2011; Jax \#020631) females. From these crosses, ePet-Cre;Drd2 ${ }^{\text {loxP/wild-type }}$ males were then bred to homozygous Drd2 $2^{\text {loxP/loxP }}$ females for ePet-Cre;Drd2 $2^{\text {loxP/loxP }}$ male and female offspring used for experiments. Experimental controls were littermates with the $D r d 2^{\text {loxP/loxP }}$ genotype thus negative for Cre but of comparable genetic background (C57BL/6J, Jax \#000664). For Drd2-Pet1 neuron cell counts, triple transgenic Drd2-Cre;Pet1-Flpe;RC-FrePe (Gong et al., 2007; Jensen et al., 2008; Brust et al., 2014; $R C$-FrePe Jax \#029486) were generated by crossing Drd2Cre females to Pet1-Flpe;RC-FrePe double transgenic males. Likewise for axonal projection mapping, Drd2-Cre; Pet1-Flpe; RC-FPSit (RC-FPSit Jax \#030206) triple transgenic mice were generated by crossing Drd2-Cre females to Pet1-Flpe;RC-FPSit double transgenic males. For both RC$F r e P e$ and $R C$-FPSit crosses, all animals of each sex were from separate litters, though males and females from the same litter were used when possible. Genotypes were determined as previously described (Brust et al., 2014). Number of animals used for each assay is listed under the description for each assay.

\section{Immunohistochemistry}

Mice were briefly anesthetized with isoflurane and immediately perfused intracardially with PBS followed by $4 \%$ paraformaldehyde (PFA) in PBS. Brains were extracted, postfixed in $4 \%$ PFA overnight at $4^{\circ} \mathrm{C}$, cryoprotected in 30\% sucrose/PBS for $48 \mathrm{~h}$, and embedded in OCT compound (Tissue-Tek). Coronal sections were cryosectioned as $30-\mu \mathrm{m}$ free-floating sections then rinsed three times with PBS for $10 \mathrm{~min}$, blocked in 5\% normal donkey serum (NDS; Jackson ImmunoResearch) and permeabilized with $0.1 \%$ Triton $\mathrm{X}-100$ in PBS for $1 \mathrm{~h}$ at room temperature. Sections were incubated for $24-48 \mathrm{~h}$ in primary antibodies in the same blocking buffer at $4^{\circ} \mathrm{C}$. Primary antibodies used were goat polyclonal anti-5-HT (1:1000, catalog \#ab66047; Abcam), chicken polyclonal anti-GFP (1:2000, RRID: AB_2307313; AVES), rabbit polyclonal anti-DsRed (1:1000; catalog \#632496; Clontech), and rabbit anti-GABA (1:500, catalog \#A2052; Sigma). Following primary antibody incubation, sections were rinsed three times with PBS for 10 min and incubated in secondary antibody (Alexa Fluor 488 donkey anti-chicken IgY, 703-545-155, Jackson ImmunoResearch; Alexa Fluor 546 donkey anti-rabbit IgG, A10040, Invitrogen; Alexa Fluor 647 donkey anti-goat lgG, A-21447, Invitrogen) for $1 \mathrm{~h}$ at room temperature, rinsed three times with PBS for $10 \mathrm{~min}$, then mounted using ProLong Gold Antifade Mountant (P36930, LifeTechnologies). For Drd2-Pet1 neuron cell counts, GFP + cells were counted in every sixth section. The 
resulting number was multiplied by 6 to obtain the number of Drd2-Pet1 cells per animal.

\section{Dual immunohistochemistry and fluorescent in situ hybridization (FISH)}

For dual in situ hybridization with immunostaining for GFP+ Drd2-Pet1 neuron cell bodies, PFA-perfused brain tissue from adult Drd2-Cre;Pet1-Flpe; $R C$-FrePe mice was collected as described above but cryosectioned at $20 \mu \mathrm{m}$ onto slides (Superfrost Plus, catalog \#48311-703, WWR), slides were warmed on a slide warmer set to $45^{\circ} \mathrm{C}$ for $30 \mathrm{~min}$, and processed with RNAscope Multiplex Fluorescent Assay kit (Advanced Cell Diagnostics) following manufacturer's protocol with the exception that at the end of the protocol, tissue was stained for anti-GFP, as described above, similar to Shrestha et al. (2018). The following probes were used for the dual protocol: Dmd (catalog \#561551-C3), Drd2-E2 (catalog \#486571-C2), Gad2 (catalog \#439371-C2), and Serpini1 (catalog \#501441). Cell nuclei were visualized with 4',6-diamidino-2-phenylindole (DAPI).

\section{FISH}

For FISH validation of Drd2 conditional knockout and Gad2 expression analysis, adult $\operatorname{Drd} 2^{\text {Pet1-CKO }}$ or control brain tissue was fresh frozen in OCT (TissueTek) and cryosectioned at $16 \mu \mathrm{m}$ onto slides (Superfrost Plus, catalog \#48311-703, VWR) and then processed with RNAscope Multiplex Fluorescent Assay kit (Advanced Cell Diagonstics) following manufacturer's protocol for fresh frozen tissue. The following probes were used: Drd2-E2 (catalog \#486571-C2), Drd2-O4 (Exon7/8; catalog \#534241), Fev (Pet1) (catalog \#413241-C3), Gad2 (catalog \#439371-C2), Tph2 (catalog \#318691), and cre (catalog \#312281). Cell nuclei were visualized with DAPI.

\section{Image collection}

All images were acquired on a Nikon Ti inverted spinning disk confocal microscope with 488-, 561-, 647-nm laser lines and Andor Zyla 4.2 Plus sCMOS monochrome camera. Images were acquired with Nikon Elements Acquisition software AR 5.02. For RNA quantification and $\operatorname{Drd2}{ }^{\text {Pet1-CKO }}$ validation experiments, four images were taken of brain slices containing the DR: the first directly ventral to the aqueduct then one field of view below and to the left and right to capture each lateral wing.

\section{FISH quantification}

Quantification was conducted blind to sex and genotype. For Drd2 ${ }^{\text {Pet1-CKO }}$ validation, all Pet1 + (serotonergic) neurons within each image were identified, then the viewer outlined the DAPI-stained nuclei of each Pet1+ neuron and scored the presence of Drd2 puncta as "positive" (having puncta) or "negative" (no puncta). The total number of Drd2 + Pet1 + neurons was then divided by the total number of Pet $1+$ neurons to yield the "\% Drd2 + Pet1 + neurons."

For quantification of Dmd, Drd2, Gad2, and Serpini1 manual counting of each mRNA punctum per cell was conducted by a trained viewer. All cells counted fit the criteria of GFP+ with a DAPI+ nucleus. The viewer outlined the GFP+ cell body in FIJI (https://Fiji.sc/; Schindelin et al., 2012) while only viewing that channel and then counted the number of distinct RNA puncta within that cell outline. Brain sections sampled were from five males and five female animals.

For quantification of Drd2-Exon7/8 and Gad2 puncta in Drd2 ${ }^{\text {Pet1-CKO }}$ tissue, DR sections corresponded to interaural -0.80 to $1.04 \mathrm{~mm}$ and bregma -4.60 to $-4.84 \mathrm{~mm}$ based on DAPI staining and anatomic landmarks (Franklin and Paxinos, 2008), where Drd2-Pet1 neurons are most enriched. A series of custom FIJl scripts and a CellProfiler (McQuin et al., 2018) pipeline were used to process and analyze confocal images of RNAscope FISH signal in a semi-automatic manner. Analysis was performed in 2D on maximum intensity projections of 6 - $\mu \mathrm{m}$-thick $z$-stacks. First, a (step 1) preprocessing FIJI script separated channels and preprocessed them for (step 2) CellProfiler to use as input to segment nuclei. The DAPI-stained channel was preprocessed by a Gaussian blur with a diameter of 18 before segmenting with the IdentifyPrimaryObjects module with a diameter range $30-100$ pixels using a minimum cross entropy global thresholding strategy. Objects outside of the diameter range or those on the edges were excluded. A threshold smoothing scale of 1.3488 was used and the image was automatically declumped based on intensity values. Finally, holes were filled in the resulting label map image, which was exported for use in FIJI (step 3). In FIJI, the user manually excluded misidentified objects or added additional nuclei that were missed by the automatic detection pipeline. A highly similar script was recently published (Okaty et al., 2020), though this current script performs additional difference of Gaussian (Marr and Hildreth, 1980) based filtering for each FISH channel. For each FISH probe, after background subtraction with a rolling ball radius of 50 pixels, the image was duplicated and a Gaussian blur was performed at two different $\sigma$ levels, one which obscured small background pixels but preserved mRNA puncta, and a more extreme blur that only retained larger diffuse background puncta. The difference of these two images was then calculated and puncta localized using the Find Maxima function. To find appropriate settings for each FISH channel, we compared the performance of several sets of parameters to automatically detect puncta versus a hand count of puncta. We were able to achieve excellent concordance between the hand count and automatic puncta detection. Table 1 summarizes our settings and performance in a linear regression against the hand count for each FISH probe (statistics calculated in GraphPad Prism v8.4.3 and Microsoft Excel v2002).

\section{Behavioral assays}

All assays, except the resident-intruder assay, were conducted in an initial cohort of 15 control (eight males, seven females) and $11 \mathrm{Drd} 2^{\text {Pet1-CKO }}$ (six males, five females) mice. All behavioral assays were conducted at postnatal day (P)90 or later. The run order for the initial cohort was open field, elevated plus maze, tail suspension test, forced swim test, social interaction, acoustic startle response, prepulse inhibition of acoustic startle, water T- 
Table 1: Settings for Gad2 quantification in Drd2 ${ }^{\text {Pet1-CKO }}$ tissue

\begin{tabular}{llrllll}
\hline Probe & S1 & S2 & Prominence & $R^{2}$ & RMSE & MAE \\
\hline E2 & 0.25 & 1 & 175 & 0.8696 & 0.5957 & 0.2458 \\
E7/8 & 0.5 & 1 & 100 & 0.9421 & 0.8054 & 0.35 \\
Cre & 0.5 & 1 & 100 & 0.9679 & 3.829 & 2.2244 \\
Fev & 0.25 & 2 & 75 & 0.9555 & 4.414 & 3.7047 \\
Gad2 & 0.25 & 16 & 150 & 0.8568 & 2.804 & 1.7973
\end{tabular}

Summary of settings and performance in a linear regression for semi-automated protocol versus hand counts for each FISH probe.

maze, contextual fear conditioning, tube test of social dominance and rotarod. An additional cohort of 16 controls (seven males, nine females) $D r d 2^{\text {Pet1-CKO }}$ (six males, 10 females) was run for acoustic startle response. Resident-intruder assay of aggression was conducted in three separate cohorts of mice totaling 24 control and 26 $\operatorname{Drd2} 2^{\text {Pet1-CKO }}$ males. The tube test of social dominance was run in the initial cohort and in the second (eight control and Drd2 $2^{\text {Pet1-CKO }}$ males) and third (11 control and $\operatorname{Drd} 2^{\text {Pet1-CKO }}$ males) aggression cohorts for a total of 24 control and Drd2 $2^{\text {Pet1-CKO }}$ males and a separate cohort of 16 control and $18 \mathrm{Drd2}{ }^{\text {Pet1-CKO }}$ females. The rotarod assay was also repeated in a separate cohort of males (seven controls, six Drd2 ${ }^{\text {Pet1-CKO}}$ ). Experiments were conducted between zeitgeber time (ZT)6 and ZT10, with interspersion of control and experimental animals, and assays were run and analyzed by a trained experimenter blinded to genotype. The open field test, elevated plus maze, tail suspension test, forced swim test, social interaction, prepulse inhibition of acoustic startle, water T-maze, and contextual fear conditioning were performed as previously described (Niederkofler et al., 2016). All other behavioral assays are described in detail below.

\section{Rotarod}

The rotarod apparatus (Stoelting; Ugo Basile Apparatus) contains a rotating rod set to an accelerating speed. Mice are placed onto the rod and rotation of the rod begins. When a mouse loses its balance and falls, the apparatus automatically stops and measures the latency and rotating speed at which the mouse fell. Training consisted of exposing the mice to the apparatus for $5 \mathrm{~min}$ at a constant speed of $4 \mathrm{rpm}$. Mice that fall during the training session are placed back on the apparatus until the training session time has elapsed. An hour following the training session, mice are placed back on the rod for a 2-min session in which speed increases steadily over $2 \mathrm{~min}$ from 5 to $40 \mathrm{rpm}$. If a mouse does not fall during the $2 \mathrm{~min}$, the trial ends at $2 \mathrm{~min}$. Each animal was tested over $3 \mathrm{~d}$ and the latency to fall was averaged for each mouse. This assay was conducted in 21 control mice (14 males, seven females) and $18 \operatorname{Drd}^{\text {Pet1-CKO }}{ }_{(13}$ males, five females).

\section{Acoustic startle response}

Mice were placed in a perforated holder (acrylic cylinder with $3.2-\mathrm{cm}$ internal diameter) that allowed movement to be monitored. Animal holders were placed on top of a transducer platform, measuring the active response to both weak and startle stimuli, adjacent to a speaker, within an individual acoustic chamber (Med Associates). Each session consisted of a 5 min acclimation period followed by 10 blocks of 11 trials each with white noise acoustic stimuli (20-120 dB). Each startle stimulus (20$120 \mathrm{~dB}$, in 10-dB increments) was played once per block, in a quasi-random order with a variable intertrial interval of 10-20 s (average of $15 \mathrm{~s}$ ). The duration of the stimulus was $40 \mathrm{~ms}$. Responses were recorded for $150 \mathrm{~ms}$ from startle onset and are sampled every ms. Mice were placed back into the home cage immediately after testing. Males and female were run on different days. This assay was conducted in 30 control mice (14 males, 16 females) and $28 \mathrm{Drd2}^{\text {Pet1-CKO }}$ (13 males, 15 females), as two separate cohorts per sex.

\section{Tube test of social dominance}

Two age-matched ( $\sim$ P90), weight-matched mice of the same sex are introduced into opposite ends of a clear PVC tube $(30.5 \mathrm{~cm}$ in length with an internal diameter of $2.5 \mathrm{~cm}$ ) allowing them to interact in the middle but not pass each other within the tube. The subordinate mouse will back out allowing the dominant mouse to pass through (Lindzey et al., 1961). For each pair, five consecutive trials were run with a maximum time of $2 \mathrm{~min}$ per trial. Trials ended when one mouse backed out of the tube such that all four limbs are outside of the tube which was then recorded as a "backout" for that mouse. Matches lasting $>2$ min were excluded from analysis and scored as a draw. Side of introduction to the tube were alternated between trials and the tube was cleaned with ethanol between each trial. Opponents were from different litters and had never been housed together. This assay was conducted in $24 \mathrm{Drd} 2^{\text {Pet1-CKO }}$ males versus 24 control males and 23 Drd2 ${ }^{\text {Pet } 1 \text {-CKO }}$ females versus 23 control females, conducted across three cohorts of animals.

\section{Resident-intruder assay}

$D r d 2^{\text {Pet1-CKO }}$ or control mice were group-housed with male siblings until adulthood (P90) when they were singlehoused for one night in the test cage to establish territorial residency. On day 1, a five-week-old Swiss Webster (Charles River) male, the "intruder," was introduced to the cage divided with a clear perforated divider for $5 \mathrm{~min}$. After $5 \mathrm{~min}$, the perforated divider was removed, and the mice could interact for $5 \mathrm{~min}$, in which the encounter was video recorded. Number of attack bites were counted by a trained, blinded viewer. The intruder mouse was introduced for $3 \mathrm{~d}$ to obtain an average number of attack bites per day. The intruder mouse had a lower body weight than the resident male. This assay was conducted only in males, as female laboratory-reared mice do not display territorial aggression (Palanza, 2001; Lonstein and Gammie, 2002) This assay was conducted in $26 \operatorname{Drd2}^{\text {Pet1-CKO }}$ and 24 controls.

\section{Auditory brainstem response (ABR)}

$A B R s$ were recorded in a separate cohort of adult mice (males: 10 control and seven Drd2 ${ }^{\text {Pet1-CKO; females: eight }}$ control and seven Drd2 ${ }^{\text {Pet1-CKO }}$ ) aged P71-P102 to correspond to the age of animals in other assays. ABRs were conducted similar to (Maison et al., 2013). Mice were 
anesthetized by intraperitoneal injection of ketamine $(100 \mathrm{mg} / \mathrm{kg})$ and xylazine $(7.5 \mathrm{mg} / \mathrm{kg})$ and placed in a soundproof chamber on a heating pad. Acoustic stimuli were delivered using EPL Cochlear Function Test Suite (CFTS) software and analyzed using ABR peak analysis software [1.1.1.9, Massachusetts Eye and Ear (MEE)]. All ABR thresholds, amplitudes, and latencies were read by an investigator blind to mouse genotype.

\section{Electrophysiology}

Slice preparation and whole-cell patch-clamp recordings were conducted as previously described (Rood et al., 2014; Niederkofler et al., 2016). Briefly, to assess membrane and action potential (AP) characteristics a protocol of repeated sweeps of 500-ms current injections stepping in $20-p A$ steps from -80 to $180 \mathrm{pA}$ was administered to cells in current clamp. Data were analyzed using Clampfit (Molecular Devices). Some cells included in cell property analyses were also used to generate data on the function of DRD2 receptors in the DR (Niederkofler et al., 2016). However, the intrinsic cell properties data we present in this article have not been previously published and include cells not part of the Niederkofler et al. (2016) dataset.

\section{Projection mapping}

Brain tissue from six females and five males from different litters, but with a female and male from the same litter where possible, were collected at P90 and processed as previously described (Niederkofler et al., 2016). Target region identification was based on anatomic landmarks identified by DAPI staining, anti-choline acetyltransferase (goat polyclonal anti-ChAT,1:500, AB144P; EMD234 Millipore) staining, and/or anti-tyrosine hydroxylase (rabbit anti-TH, 1:1000, AB152, Millipore) staining. Staining and imaging protocols were identical among the eleven samples analyzed.

\section{Quantification of target innervation}

Target innervation was quantified in a similar manner to (Niederkofler et al., 2016). Briefly, image stacks were acquired bilaterally per brain region analyzed for each animal using a Nikon Ti inverted spinning disk microscope with a Plan Fluor $40 \times / 1.3$ Oil DIC H/N2 objective, 488-, 561-, and 647-nm laser lines, and Andor Zyla 4.2 Plus sCMOS monochrome camera. Images were acquired with Nikon Elements Acquisition software AR 5.02. Image stacks (.nd2 files) were imported to FIJI for analysis of axon projection area. Each stack contained 21 optical slices of $0.3 \mu \mathrm{m}$. Innervation density was quantified by a FIJI macro, such that all images, were treated identically, including background subtraction, thresholding and particle counting as described in (Niederkofler et al., 2016). We then divided the total area occupied by the projection signal by the total area of the 21 optical slices to obtain the percent area occupied by projection signal. This was then averaged within images of the same brain region across male or female samples. Brain regions analyzed were either those previously described to be innervated by Drd2-
Pet1 neurons in males only (Niederkofler et al., 2016) or those involved in auditory processing and ASR.

\section{Statistical analyses}

Data are presented as mean \pm SEM. Statistical analyses were conducted in GraphPad Prism version 8.1. Statistical significance was determined by unpaired $t$ test between control versus Drd2 ${ }^{\text {Pet1-CKO }}$ groups or male versus female groups except where noted: open field, forced swim test, acoustic startle response, and ABR statistical significance was determined using two-way ANOVA. For the resident-intruder assay, the tube test of social dominance, and rotarod, statistical significance was determined using the non-parametric Mann-Whitney $U$ test. A result was considered significant if $p<0.05$. Detailed statistical results are reported in Table 2 .

\section{Results}

\section{Visualization of Drd2-Pet1 serotonergic neurons and the loss of Drd2 gene expression in Drd2 ${ }^{P e t 1-C K O}$ mice}

As our first step, we confirmed the anatomic distribution of Drd2-Pet1 neurons in the mouse brainstem, observing cell soma distributed across the rostral and lateral regions of the DR nucleus (Fig. 1A) as previously reported (Niederkofler et al., 2016). Drd2-Pet1 cells were marked by GFP expression in triple transgenic Drd2-Cre;Pet1-Flpe;RC-Frepe (Gong et al., 2007; Jensen et al., 2008; Brust et al., 2014) mice in which cells positive for both Cre and Flpe activity - here those cells having expressed Drd2 and Pet1 - have recombined the $R C$-FrePe intersectional reporter allowing GFP expression; Flpe recombination alone configured $R C$-FrePe to drive mCherry expression, thus marking the remaining Pet1 + (Drd2-negative) serotonergic neurons (Fig. 1A,B). As expected (Niederkofler et al., 2016), GFP + Drd2-Pet1 neurons showed detectable 5-HT by immunostaining and Drd2 mRNA by fluorescent in situ hybridization (FISH) (Fig. 1C).

To query the behavioral requirement for Drd2 gene expression in Drd2-Pet1 neurons, we deployed the ePet-cre driver (Scott et al., 2005) to delete floxed Drd2 gene sequences (Bello et al., 2011), creating a functional null Drd2 allele selectively in Pet1 neurons (Fig. 1D), and then subjected these Drd2 $2^{P e t 1-C K O}$ mice to behavioral phenotyping. Cre-negative, Drd $2^{\text {flox/flox }}$ littermates served as controls. To confirm loss of Drd2 gene expression in Pet1 neurons, we analyzed Drd2 $2^{\text {Pet1-CKO }}$ and control Drd2 $2^{\text {flox/flox }}$ brain tissue sections by mRNA in situ hybridization using a probe designed to detect exon 2-containing Drd2 mRNA, as exon 2 was the floxed gene portion to be excised by Cre recombination; concomitant identification of serotonergic neurons was by detection of Pet1 transcripts (Fig. 1F,G). Robust loss of Drd2 expression was observed in serotonergic neurons in both male and female mice [15.23 $\pm 2.41 \%$ of Pet1 + neurons in the DR express Drd2 transcripts in controls $(n=6)$, consistent with prior findings, compared with $3.87 \pm 0.73 \%$ in Drd2 ${ }^{\text {Pet1-CKO }} \mathrm{S}(n=6), p=0.0011$, unpaired $t$ test; Fig. 1E]. The few residual Pet1+ cells harboring Drd2 transcripts likely reflects a limitation in cell capture by the 
Table 2: Statistical analysis

\begin{tabular}{|c|c|c|c|c|c|c|}
\hline \multirow[b]{2}{*}{ Behavior/experiment } & \multirow[b]{2}{*}{ Line } & \multicolumn{2}{|l|}{ Data structure } & \multicolumn{3}{|l|}{ Power } \\
\hline & & (normality) & Type of test & Comparison & F/df & $p$ \\
\hline Validation of Drd2 CKO & $1 E$ & Yes & Unpaired $t$ test & Control vs $\operatorname{Drd} 2^{\text {Pet1-CKO }}$ & $t=4.514, \mathrm{df}=10$ & $p=0.0011$ \\
\hline \multirow[t]{3}{*}{ Open field distance } & $2 A$ & Yes & Repeated-measures ANOVA & F1, genotype & $F_{(1,24)}=0.6405$ & $p=0.4314$ \\
\hline & & & & F2, time & $F_{(11,264)}=47.99$ & $p<0.0001$ \\
\hline & & & & $(\mathrm{F} 1 \times \mathrm{F} 2)$ & $F_{(11,264)}=0.8441$ & $p=0.5960$ \\
\hline Open field \% distance traveled & $2 B$ & Yes & Unpaired $t$ test & Control vs $\operatorname{Drd} 2^{\text {Pet } 1 \text {-CKO }}$ & $t=1.781, \mathrm{df}=24$ & $p=0.0876$ \\
\hline Rotarod & $2 C$ & No & Mann-Whitney, two-tailed & Control vs $\operatorname{Drd} 2^{\text {Pet1-CKO }}$ & $M-W U=142$ & $p=0.1899$ \\
\hline Elevated plus maze (\% time in open arm) & $2 D$ & Yes & Unpaired $t$ test & Control vs $\operatorname{Drd} 2^{\text {Pet1-CKO }}$ & $t=1.250, \mathrm{df}=24$ & $p=0.2234$ \\
\hline Tail suspension test & $2 E$ & Yes & Unpaired $t$ test & Control vs $\operatorname{Drd} 2^{\text {Pet1-CKO }}$ & $t=0.3485, \mathrm{df}=24$ & $p=0.7305$ \\
\hline \multirow[t]{3}{*}{ Forced swim test } & $2 F$ & Yes & Repeated-measures ANOVA & F1, genotype & $F_{(1,24)}=0.2678$ & $p=0.6095$ \\
\hline & & & F2, time & $F_{(5,120)}=8.916$ & $p<0.0001$ & \\
\hline & & & $(\mathrm{F} 1 \times \mathrm{F} 2)$ & $F_{(5,120)}=0.3090$ & $p=0.9067$ & \\
\hline Contextual fear conditioning (baseline freezing) & $2 G$ & Yes & Unpaired $t$ test & Control vs $\operatorname{Drd} 2^{\text {Pet1-CKO }}$ & $t=0.6682, \mathrm{df}=24$ & $p=0.5104$ \\
\hline Contextual fear conditioning (test freezing) & & & Unpaired $t$ test & Control vs $\operatorname{Drd} 2^{\text {Pet1-CKO }}$ & $t=0.0127, \mathrm{df}=24$ & $p=0.9900$ \\
\hline \multirow[t]{3}{*}{ Water T maze (\%correct during acquisition) } & $2 H$ & Yes & Repeated-measures ANOVA & F1, genotype & $F_{(1,24)}=0.08249$ & $p=0.7764$ \\
\hline & & & & $\mathrm{F} 2$, time & $F_{(4,89)}=50.12$ & $p<0.0001$ \\
\hline & & & & $(\mathrm{F} 1 \times \mathrm{F} 2)$ & $F_{(4,89)}=0.6698$ & $p=0.6147$ \\
\hline \multirow[t]{3}{*}{ Water T maze (\%correct during reversal) } & & Yes & Repeated-measures ANOVA & F1, genotype & $F_{(1,24)}=0.1631$ & $p=0.6899$ \\
\hline & & & & F2, time & $F_{(4,96)}=172.4$ & $p<0.0001$ \\
\hline & & & & $(\mathrm{F} 1 \times \mathrm{F} 2)$ & $F_{(4,96)}=1.477$ & $p=0.2153$ \\
\hline \multirow[t]{3}{*}{ ASR (M) } & $3 C$ & Yes & Repeated-measures ANOVA & F1, genotype & $F_{(1,25)}=0.0840$ & $p=0.7745$ \\
\hline & & & & $\mathrm{F} 2, \mathrm{~dB}$ & $F_{(10,250)}=28.99$ & $p<0.0001$ \\
\hline & & & & $(\mathrm{F} 1 \times \mathrm{F} 2)$ & $F_{(10,250)}=0.3037$ & $p=0.9798$ \\
\hline \multirow[t]{2}{*}{ ASR habituation (M) } & $3 D$ & Yes & Pearson $r$ correlation & Control trial number $\times$ startle response & $r=-0.195$ & $p=0.5893$ \\
\hline & & & & $\operatorname{Drd} 2^{\text {Pet1-CKO }}$ trial number $\times$ startle response & $r=0.136$ & $p=0.7079$ \\
\hline \multirow[t]{3}{*}{ ASR latency (M) } & $3 E$ & Yes & Repeated-measures ANOVA & F1, genotype & $F_{(1,25)}=2.425$ & $p=0.1319$ \\
\hline & & & & $\mathrm{F} 2, \mathrm{~dB}$ & $F_{(10,250)}=21.67$ & $p<0.0001$ \\
\hline & & & & $(\mathrm{F} 1 \times \mathrm{F} 2)$ & $F_{(10,250)}=0.4722$ & $p=0.9071$ \\
\hline \multirow[t]{3}{*}{ ASR (F) } & $3 F$ & Yes & Repeated-measures ANOVA & F1, genotype & $F_{(1,29)}=13.26$ & $p=0.0011$ \\
\hline & & & & $\mathrm{F} 2, \mathrm{~dB}$ & $F_{(10,29)}=35.29$ & $p<0.0001$ \\
\hline & & & & $(\mathrm{F} 1 \times \mathrm{F} 2)$ & $F_{(10,290)}=7.475$ & $p<0.0001$ \\
\hline \multirow[t]{2}{*}{ ASR habituation $(F)$} & $3 G$ & Yes & Pearson $r$ correlation & Control trial number $\times$ startle response & $r=0.1171$ & $p=0.7473$ \\
\hline & & & & $\operatorname{Drd} 2^{P e t 1-C K O}$ trial number $\times$ startle response & $r=0.05165$ & $p=0.8873$ \\
\hline \multirow[t]{3}{*}{ ASR latency (F) } & $3 H$ & Yes & Repeated-measures ANOVA & F1, genotype & $F_{(1,29)}=0.3748$ & $p=0.5452$ \\
\hline & & & & $\mathrm{F} 2, \mathrm{~dB}$ & $F_{(10,290)}=20.59$ & $p<0.0001$ \\
\hline & & & & $(\mathrm{F} 1 \times \mathrm{F} 2)$ & $F_{(10,290)}=1.058$ & $p=0.3953$ \\
\hline \multirow[t]{3}{*}{$\mathrm{PPI}(\mathrm{M})$} & $3 l$ & Yes & Repeated-measures ANOVA & F1, genotype & $F_{(1,12)}=0.6625$ & $p=0.4315$ \\
\hline & & & & F2, prepulse dB & $F_{(2,24)}=42.86$ & $p<0.0001$ \\
\hline & & & & $(\mathrm{F} 1 \times \mathrm{F} 2)$ & $F_{(2,24)}=4.104$ & $p=0.0293$ \\
\hline $\mathrm{PPI}(\mathrm{F})$ & $3 \mathrm{~J}$ & Yes & Repeated-measures ANOVA & F1, genotype & $F_{(1,10)}=0.6526$ & $p=0.4380$ \\
\hline & & & & $\mathrm{F} 2$, prepulse $\mathrm{dB}$ & $F_{(2,20)}=31.34$ & $p<0.0001$ \\
\hline & & & & $(\mathrm{F} 1 \times \mathrm{F} 2)$ & $F_{(2,20)}=1.609$ & $p=0.2249$ \\
\hline ABR amplitude (M) & $4 C$ & Yes & Repeated-measures ANOVA & F1, genotype & $F_{(1,15)}=1.770$ & $p=0.2032$ \\
\hline & & & & F2, peak & $F_{(2,30)}=59.09$ & $p<0.0001$ \\
\hline & & & & $(\mathrm{F} 1 \times \mathrm{F} 2)$ & $F_{(2,30)}=1.059$ & $p=0.3595$ \\
\hline ABR latency (M) & $4 D$ & Yes & Repeated-measures ANOVA & F1, genotype & $F_{(1,15)}=3.515$ & $p=0.0804$ \\
\hline & & & & F2, peak & $F_{(2,30)}=1171$ & $p<0.0001$ \\
\hline & & & & $(\mathrm{F} 1 \times \mathrm{F} 2)$ & $F_{(2,30)}=3.121$ & $p=0.0587$ \\
\hline ABR threshold (M) & $4 E$ & & & & & \\
\hline 5.6 & & Yes & Unpaired $t$ test & Control vs Drd2 ${ }^{\text {Pet1-CKO }}$ & $t=0.9535, \mathrm{df}=14$ & $p=0.3565$ \\
\hline 8 & & Yes & Unpaired $t$ test & Control vs $\operatorname{Drd} 2^{\text {Pet1-CKO }}$ & $t=1.894, \mathrm{df}=14$ & $p=0.0791$ \\
\hline 16 & & Yes & Unpaired $t$ test & Control vs $\operatorname{Drd} 2^{\text {Pet1-CKO }}$ & $t=1.103, \mathrm{df}=14$ & $p=0.2887$ \\
\hline 32 & & Yes & Unpaired $t$ test & Control vs $\operatorname{Drd} 2^{\text {Pet1-CKO }}$ & $t=2.129, \mathrm{df}=7$ & $p=0.0708$ \\
\hline ABR amplitude (F) & $4 F$ & Yes & Repeated-measures ANOVA & F1, genotype & $F_{(1,13)}=2.489$ & $p=0.1387$ \\
\hline & & & & F2, peak & $F_{(2,26)}=72.52$ & $p<0.0001$ \\
\hline & & & & $(\mathrm{F} 1 \times \mathrm{F} 2)$ & $F_{(2,26)}=0.0487$ & $p=0.9525$ \\
\hline ABR latency $(F)$ & $4 G$ & Yes & Repeated-measures ANOVA & F1, genotype & $F_{(1,13)}=0.0053$ & $p=0.9430$ \\
\hline & & & & F2, peak & $F_{(2,26)}=4360$ & $p<0.0001$ \\
\hline & & & & $(\mathrm{F} 1 \times \mathrm{F} 2)$ & $F_{(2,26)}=0.0822$ & $p=0.9213$ \\
\hline & & & (Continued) & & & \\
\hline
\end{tabular}


Table 2: Continued

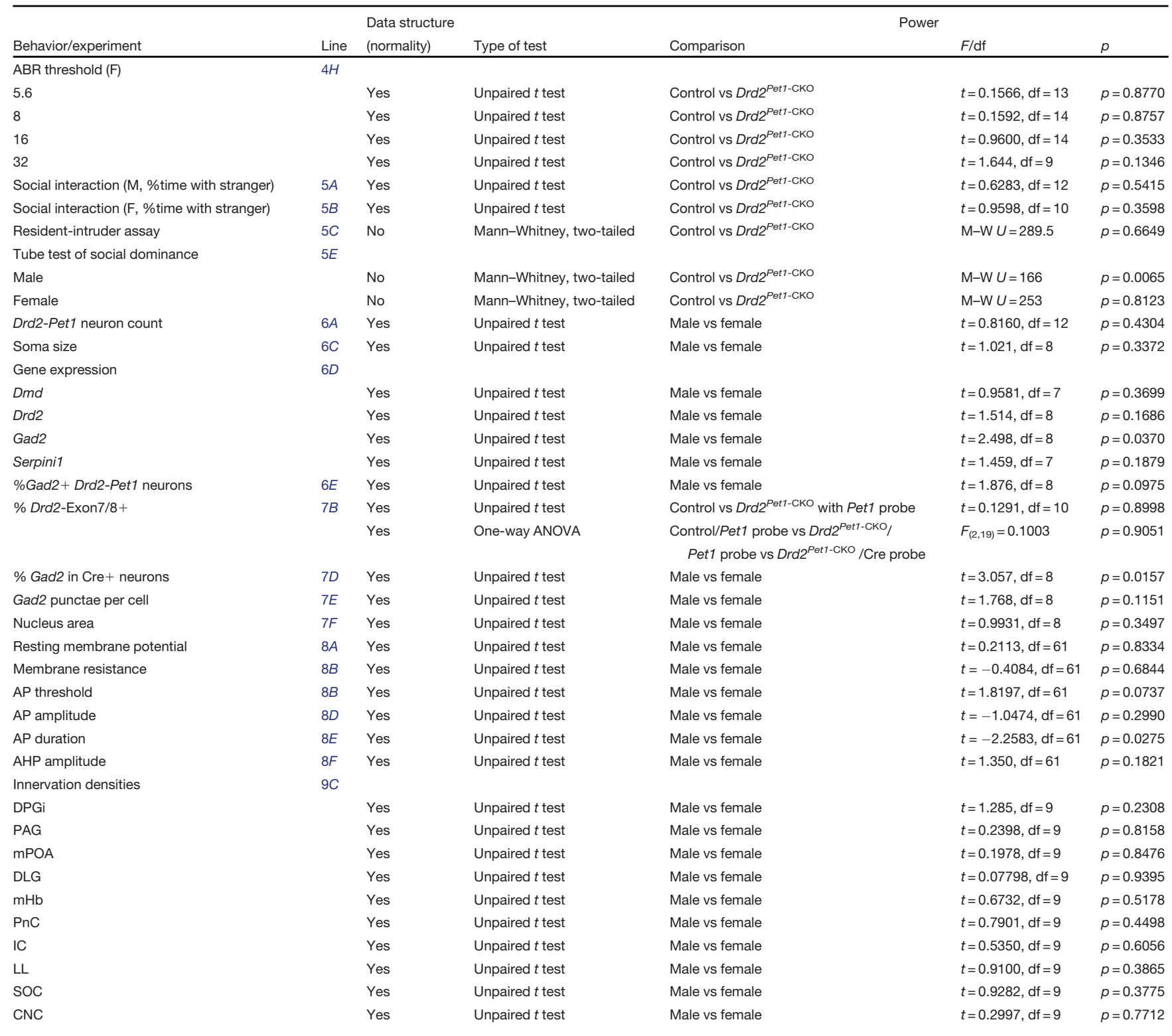

Statistical values are provided for behavioral analyses of $\operatorname{Drd2} 2^{\text {Pet1-CKO }}$ mice and comparison of Drd2-Pet1 neuron properties in male versus female mice. Figure numbers are included to reference corresponding graphs. Statistical analyses were conducted in GraphPad Prism version 8.1.

ePet-cre driver. Reliable immunodetection to confirm the expected parallel loss of DRD2 protein in PET1 cells remains unavailable.

\section{Behavioral assessments in Drd2 $2^{P e t 1-C K O}$ mice and the detection of sex-specific sensory, defensive, and social behaviors}

Having validated effective loss of Drd2 expression specific to Pet1 neurons in Drd2 ${ }^{\text {Pet1-CKO }}$ mice, next, we screened these mice for behavioral alterations in comparison to sibling control $\mathrm{Drd}^{\text {flox/flox }}$ (Cre-negative) mice. Locomotor behaviors were explored first because they are known to be influenced by serotonergic and dopaminergic manipulations (Baik et al., 1995; Gainetdinov et al.,
1999; Holmes et al., 2003; Seo et al., 2019), and because motor alterations can affect performance in and interpretation of subsequent behavioral assays. Notably, we found no differences between Drd2 ${ }^{\text {Pet1-CKO }}$ versus control mice (males or females) in the locomotor behaviors reflected in the open field and rotarod tests, such as distance traversed (Fig. 2A) and location within the field (Fig. $2 B$ ), vertical rearing, length of time on the rotating rod (Fig. 2C), which reflects balance, coordination, physical conditioning, and motor-planning. Next, we explored measures of depression-like and anxiety-like behaviors, as they are altered in various 5-HT-pathway or DA-pathway mouse models and pharmacological manipulation of these neurotransmitter systems show positive clinical effect. (Lucki, 1998; Hendricks et al., 2003; Holmes et al., 
A

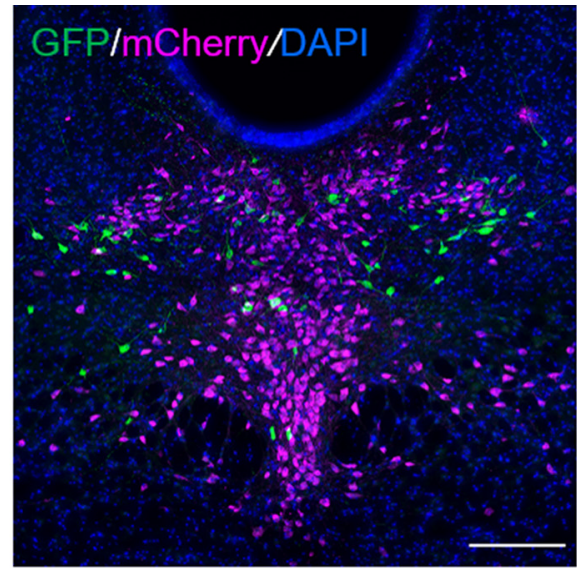

D

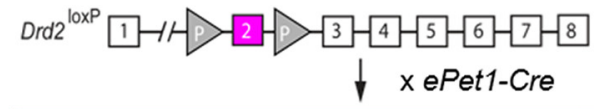

Drd2 $^{-} 1-1 / D-3-4-5-6-7-8$ i-HT neuron-specific Drd $^{\text {Loxp }} 1-1$ - $>2-3-3-4-5-6-7-8$ All other cell types
B

RC-FrePe

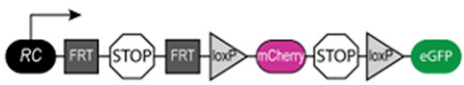

Drd2 Cre + Pet1 Fipe

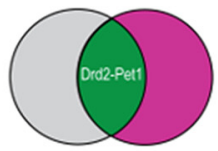

E

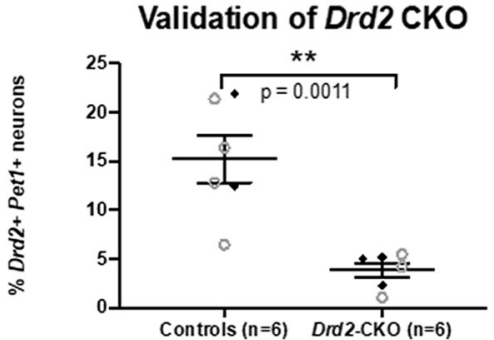

C
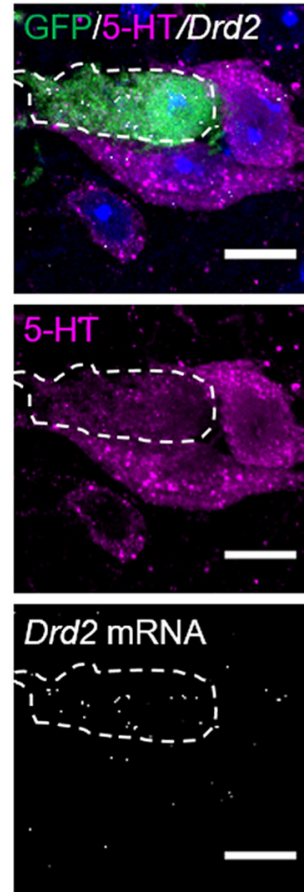

F

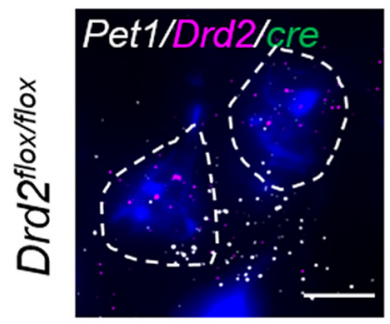

G

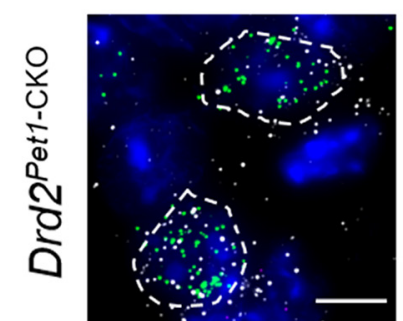

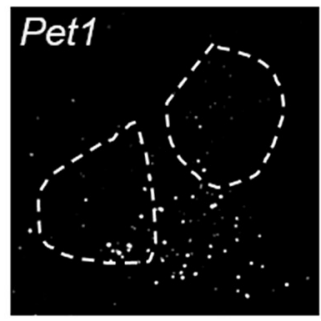

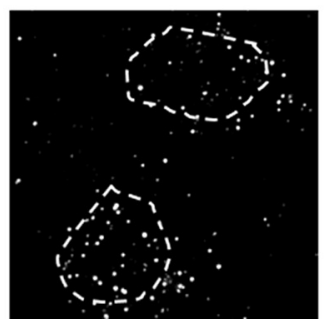

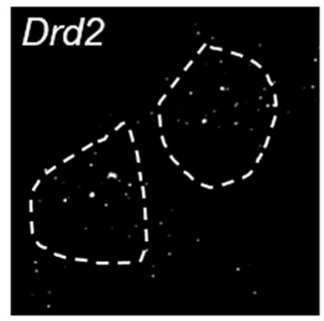

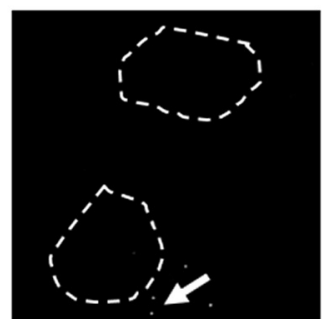

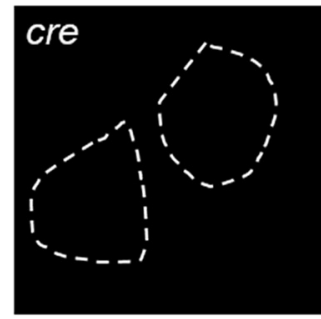

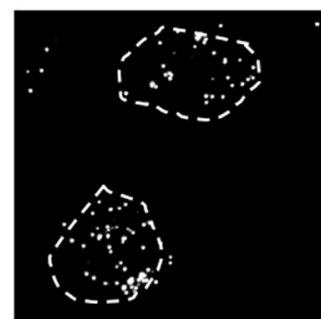

Figure 1. Visualization of Drd2-Pet1 serotonergic neurons and the loss of Drd2 gene expression in Drd2 ${ }^{\text {Pet1-CKO }}$ mice. A, Drd2-Pet1 neurons are intersectionally labeled with GFP (green) and Pet1-only positive cell bodies labeled with mCherry (magenta) in a coronal brain section of the DR from a P90 triple transgenic Drd2-Cre;Pet1-Flpe;RC:FrePe mouse. Scale bars: $200 \mu \mathrm{m}$. B, Intersectional genetic strategy: expression of Drd2-Cre and Pet1-Flpe transgenes results in dual recombination of intersectional allele, $R C$ :FrePe, labeling cells expressing Drd2 and Pet1 with GFP. C, Dual immunohistochemistry for GFP (green) and 5-HT (serotonin, magenta) coupled with FISH detection of Drd2 mRNA, which shows co-localization of intersectionally labeled Drd2-Pet1 neuron cell bodies with 5-HT and Drd2 mRNA. Scale bars: $10 \mu \mathrm{m}$. D. Strategy for conditional deletion of Drd2 in serotonergic neurons (referred to throughout as Drd2 ${ }^{\text {Pet1-CKO}}$ ). Cre recombination excises Drd2 exon 2 (magenta) producing serotonergic-specific (boxed in green) deletion of Drd2 gene sequences. $\boldsymbol{E}$, Percentage (mean \pm SEM) of Pet1+ serotonergic neurons that express Drd2 in control $(n=6)$ versus $\operatorname{Drd} 2^{\text {Pet1-CKO }}(n=6)$ shows reduction of Drd2 expression in Pet1+ neurons (controls: $15.23 \pm 2.41$ Drd2-Pet1 dual positive neurons per brain, Drd2 ${ }^{\text {Pet1-CKO: }} 3.87 \pm 0.73$ Drd2-Pet1 dual positive neurons per brain, $p=0.0011$, unpaired $t$ test). Filled black diamonds represent male mice, open gray circles represent female mice. $\boldsymbol{F}$, G, FISH on $(\boldsymbol{F})$ control and $(\boldsymbol{G}) \operatorname{Drd} 2^{P e t 1-\mathrm{CKO}}$ tissue. Drd2 transcripts detected in Pet1 + cells in control sections, but not in Drd2 Pet1-CKO mice, indicative of loss of Drd2. cre transcript is not

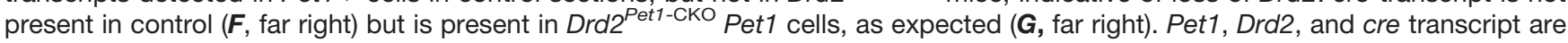
shown separately in grayscale. Note Drd2 expression remains in non-Pet1 cells (arrow). Dotted lines drawn to encircle DAPI nuclei. Scale bars: $25 \mu \mathrm{m}$. 
A

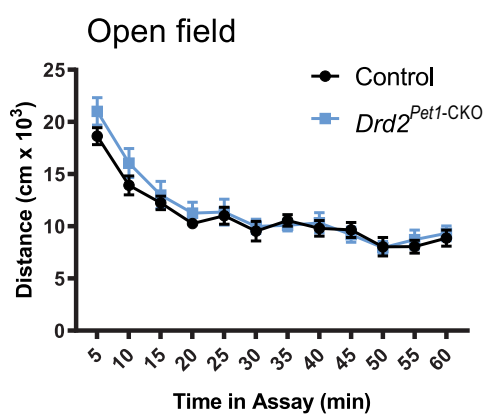

D

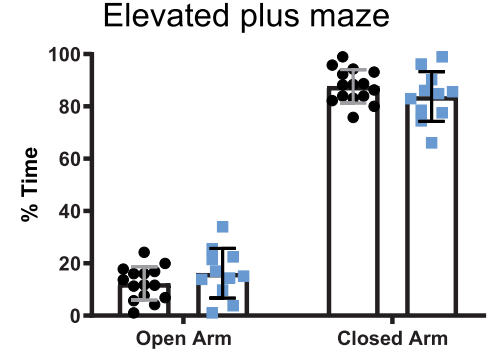

G

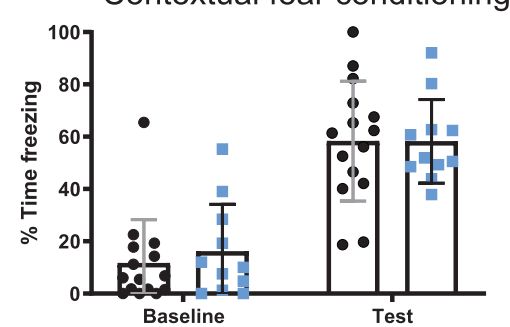

B

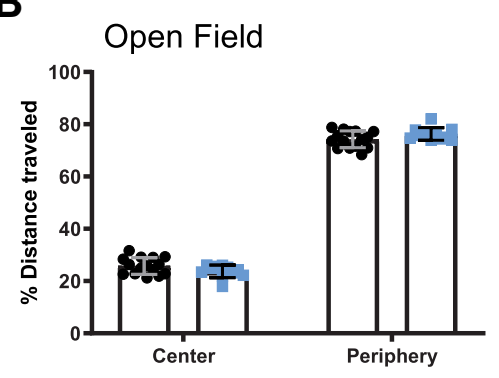

E Tail suspension test

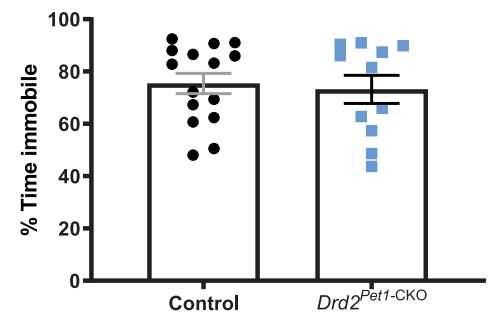

H

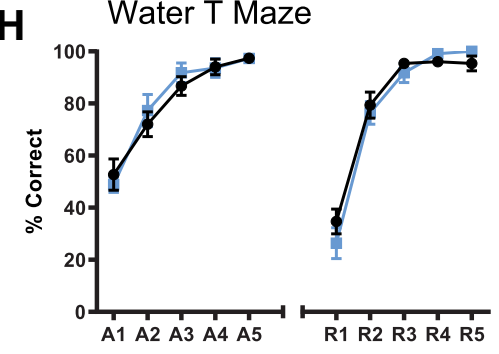

C

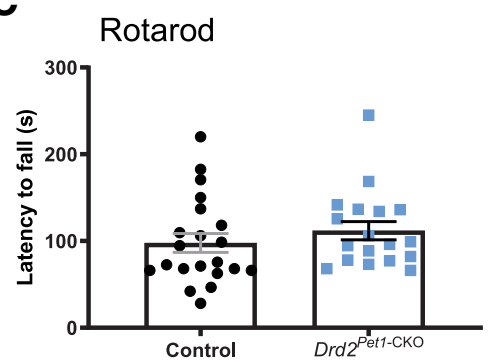

$\mathbf{F}$

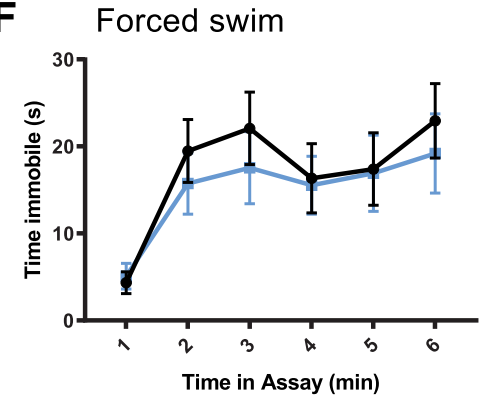

Figure 2. $\mathrm{Drd} 2^{\text {Pet1-CKO }}$ mice are largely behaviorally normal. $D r d 2^{\text {Pet1-CKO }}$ (blue symbols) mice show behaviors indistinguishable from controls (black symbols) in measures of locomotion: $(\boldsymbol{A}, \boldsymbol{B})$ open field test and $(\boldsymbol{C})$ rotarod; measures of anxiety-like and depression-like behavior: $(\boldsymbol{D})$ elevated plus maze, $(\boldsymbol{E})$ tail suspension test, and $(\boldsymbol{F})$ forced swim test; or learning and memory: $(\boldsymbol{G})$ contextual fear conditioning and $(\boldsymbol{H})$ water T maze; $n=15$ control mice (8 males, 7 females) and 11 Drd $2^{\text {Pet } 1 \text {-CKO }}$ (6 males, 5 females), except for $\boldsymbol{C}$ where, $n=21$ control mice (14 males, 7 females) and 18 Drd2 ${ }^{\text {Pet1-CKO }}$ (13 males, 5 females). Each symbol represents one animal, error bars represent SEM. No significant differences $(p>0.05)$ between Drd2 Pet1-CKO and controls were observed. No sex-specific (male vs female) phenotypes observed. For assay details, see Materials and Methods; for statistical details, see Table 2.

2003; Grace, 2016). We observed no differences in performance in the elevated plus maze (Fig. 2D), tail suspension test (Fig. 2E), or forced swim test (Fig. 2F) in Drd2 ${ }^{\text {Pet1- }}$ CKO males and females compared with littermate controls. Additionally, contextual fear conditioning (Fig. 2G) and water T-maze acquisition and reversal (Fig. $2 \mathrm{H}$ ) were not affected, suggesting no impairment of memory and learning in Drd2 ${ }^{\text {Pet1-CKO }}$ mice.

Because the serotonergic and dopaminergic systems are implicated in modulating the ASR (Davis and Aghajanian, 1976; Davis et al., 1980; Meloni and Davis, 1999, 2000a,b), we explored that next. The ASR is an evolutionarily conserved reflex involving rapid contraction of facial and skeletal muscles into a protective posture in response to a loud, threatening stimulus. We hypothesized that Drd2-Pet1 neurons modulate this response, given their dense projections to auditory brain regions (Niederkofler et al., 2016) and the observation that following acoustic startle, the activity of certain serotonergic neurons increases in the lateral wings of the $D R$ (Spannuth et al., 2011), a location in which we find Drd2Pet1 neurons. We measured startle responses to weak and startling stimuli ranging from 20 to $120 \mathrm{~dB}$ presented in a randomized order (Fig. $3 A, B$ ). Female $\operatorname{Drd} 2^{\text {Pet1-CKO }}$ mice showed a significant decrease in ASR magnitude in response to startle stimuli $\left(n=15 \operatorname{Drd2}{ }^{\text {Pet1-CKO }}, n=16\right.$ control littermates, $p=0.0011$, two-way ANOVA; Fig. $3 F$ ). By contrast, the male Drd2 Pet1-CKO cohort was indistinguishable from their male littermate controls $(n=13$ Drd2 ${ }^{\text {Pet1-CKO }}, n=14$ control littermates, $p=0.7745$, twoway ANOVA; Fig. $3 C$ ). To prevent habituation to the startle stimuli, the different stimulus intensities were presented in a quasi-random order with varied intertrial intervals (see Materials and Methods), and indeed, startle responses in late as compared with early trials were indistinguishable (shown at $110 \mathrm{~dB}$, trial number is not significantly correlated with startle magnitude, males: controls, $r=-0.1950$ and $D r d 2^{\text {Pet1-CKO }}, r=0.1360$; females: controls, $r=0.1171$ 
A

Measure startle response to 20 to $120 \mathrm{~dB}$ stimuli

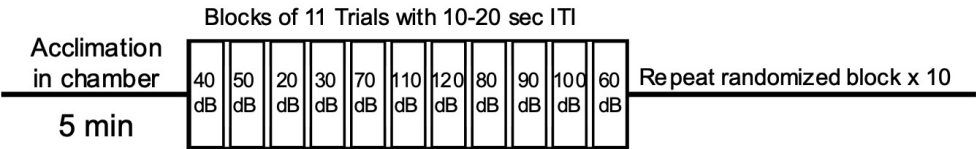

B

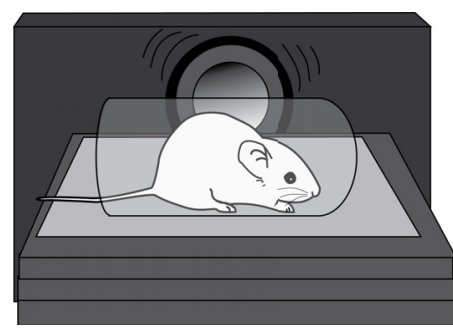

C

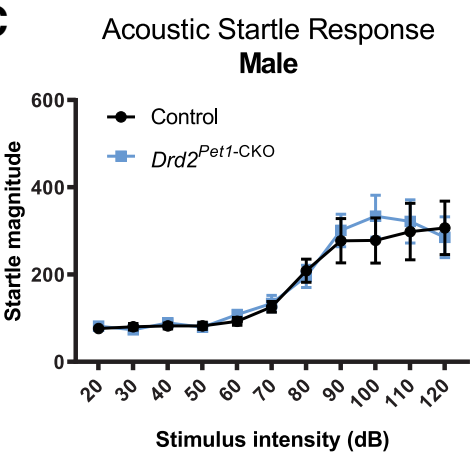

F

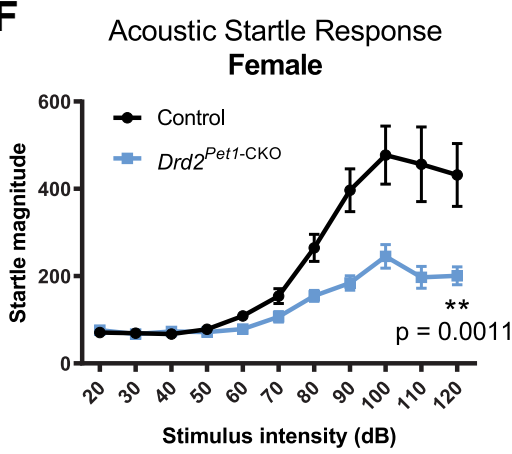

D

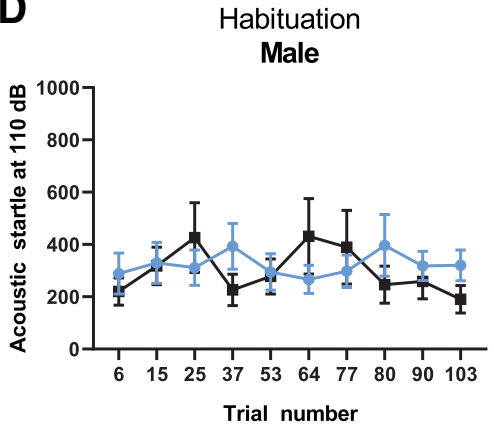

G

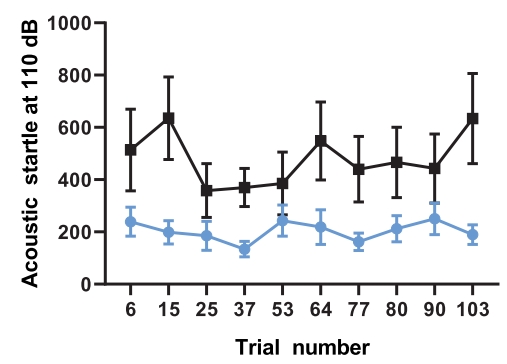

E

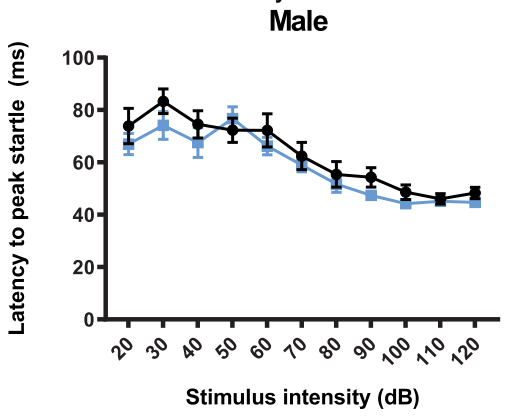

H

\section{Latency to Startle}

Female

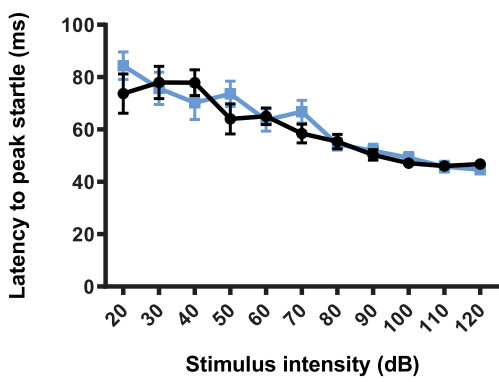

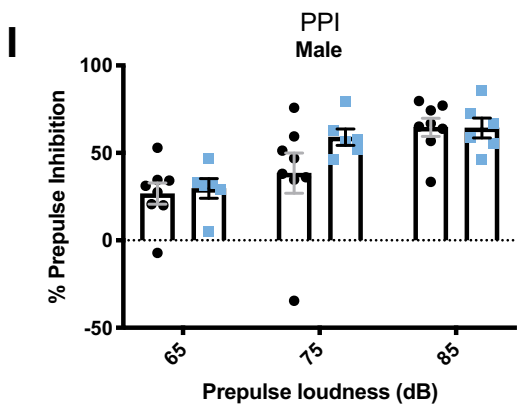

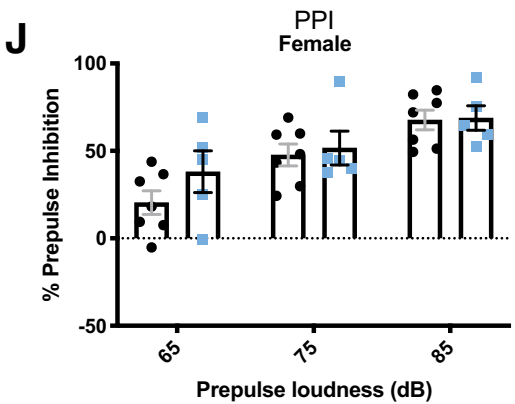

Figure 3. $D r d 2^{\text {Pet1-CKO }}$ females, but not males, display attenuated acoustic startle responses (ASR). A, Schematic of ASR experimental design. After an initial 5-min acclimation, mice are exposed to 10 blocks of 11 trials of auditory stimuli ranging from 20 to $120 \mathrm{~dB}$ in quasi-randomized order with a 10- to 20 -s intertrial interval (ITI). $\boldsymbol{B}$, Schematic of ASR measurement apparatus, mouse is placed in a perforated holding chamber atop transducer platform adjacent to speaker (for detailed description, see Materials and Methods). C, $\boldsymbol{F}$, Averaged ASR magnitudes (mean \pm SEM) across increasing stimulus intensities in (C) male Drd2 ${ }^{\text {Pet1-CKO }}$ (blue, $n=13$ ) and controls (black, $n=14$ ), no significant difference, $p=0.7745$, two-way ANOVA and $(\boldsymbol{F})$ female $D r d 2^{P e t 1-C K O}$ (blue, $n=15$ ) and controls (black, $n=16)$, Drd2 ${ }^{\text {Pet1-CKO }}$ females display significantly attenuated ASR, $p=0.0011$, two-way ANOVA. $\boldsymbol{D}$, G, Group averaged ASR for 10 trials at 110-dB stimulus in $(\boldsymbol{D})$ males and $(\boldsymbol{G})$ females, demonstrates no habituation to the startle stimulus; $x$ axis numbers refers to trial number out of 110 total trials. $\boldsymbol{E}, \boldsymbol{H}$, No significant differences in latency to startle are observed in (E) males, $p=0.1319$, two-way ANOVA and $(\boldsymbol{H})$ females, $p=0.5452$, two-way ANOVA. $\boldsymbol{I}, \boldsymbol{J}$, No significant differences in prepulse inhibition of acoustic startle are observed in $(I)$ males $\left(n=8\right.$ control, 6 Drd2 $\left.{ }^{\text {Pet1-CKO }}\right), p=0.4325$, two-way ANOVA or $(\boldsymbol{J})$ females $(n=7$ control, 5 Drd2 ${ }^{\text {Pet1-CKO }}, p=0.4380$, two-way ANOVA). 
and $D r d 2^{\text {Pet1-CKO }}, r=0.0517$, Pearson correlation; Fig. $3 D, G)$. Further, we observed no differences in latency to startle in either females or males (Fig. $3 E, H)$. Females were of similar mass (controls: $32.117 \pm 3.15 \mathrm{~g}$ vs Drd2 ${ }^{\text {Pet1-CKO: }}: 37.2 \pm 2.427 \mathrm{~g}$, unpaired $t$ test, $p=0.2031$ ) regardless of genotype, thus differences in weight and its relative impact on transduction of the startle response via the piezoelectric platform were not a confound.

While Drd2 ${ }^{\text {Pet1-CKO }}$ females showed diminished response magnitudes to startling acoustic stimuli, they nevertheless expressed normal acoustic prepulse inhibition (PPI) whereby even the diminished response to startling acoustic stimuli (e.g., 120-dB stimuli) was further blunted proportionately when immediately preceded by a weak, non-startling stimulus (e.g., 65-, 75-, or 85-dB stimuli; Fig. 3l,J). Thus, sensorimotor gating, as measured by acoustic PPI, appeared relatively intact; the acoustic dysfunction instead centered on the ASR itself.

Having observed attenuation of the ASR in female $\operatorname{Drd} 2^{\text {Pet } 1-C K O}$ mice, we assessed whether hearing was broadly disrupted as revealed by ABRs evoked by sound stimuli (Zhou et al., 2006). ABRs were recorded in response to pure tone stimuli at $5.6,8,16$, and $32 \mathrm{kHz}(n=8$ control females, $7 \mathrm{Drd2}^{\text {Pet1-CKO }}$ females, and 10 control males, $7 \mathrm{Drd} 2^{\text {Pet1-CKO }}$ males). Across all these frequencies, the measured $A B R$ waveforms (averaged $A B R$ waveforms shown at $16 \mathrm{kHz}$ at $80-\mathrm{dB}$ SPL; Fig. $4 A, B$ ), peak amplitudes [shown for peaks $1-3$ at $16 \mathrm{kHz}$ at $80-\mathrm{dB}$ SPL for males $(p=0.2032$, two-way ANOVA) and females $(p=0.1387$, two-way ANOVA); Fig. $4 C, F]$, and latencies to peaks [shown for peaks $1-3$ at $16 \mathrm{kHz}$ at $80-\mathrm{dB}$ SPL for males $(p=0.0804$, two-way ANOVA) and females $(p=0.9430$, two-way ANOVA); Fig. $4 D, G]$ were indistinguishable between Drd2 ${ }^{\text {Pet1-CKO }}$ mice and littermate controls. As well, the ABR threshold to elicit a waveform was not significantly different between $\operatorname{Drd} 2^{P e t 1-C K O}$ and control mice at 5.6, 8, 16, or $32 \mathrm{kHz}(p>0.05$ at all frequencies, unpaired $t$ test) in males (Fig. $4 E$ ) or females (Fig. $4 H$ ). Thus, hearing overall, as measured by ABR, appeared largely unaffected in $\mathrm{Drd} 2^{\text {Pet1-CKO }}$ mice.

ABRs were conducted in adult mice (ages P71-P102) to align with the age at which the other behavioral assays were performed. However at such ages, C57BL/6 mice, the strain background here, exhibit some age-related hearing loss at higher frequencies (Kane et al., 2012), which we saw here at $32 \mathrm{kHz}$ with two control and three $\operatorname{Drd} 2^{\text {Pet1-CKO }}$ females and five control and three Drd2 ${ }^{\text {Pet1-CKO }}$ males. At all other tested frequencies, the ABRs were effectively normal for both genotypes, with one exception being a Drd2 ${ }^{\text {Pet1-CKO }}$ female that exhibited undetectable ABRs at $5.6 \mathrm{kHz}$, but otherwise normal responses at all other frequencies tested including $32 \mathrm{kHz}$. These findings at 32 and $5.6 \mathrm{kHz}$ are likely independent of the ASR phenotype observed in females because all animals had normal hearing at 8 and $16 \mathrm{kHz}$, frequencies included in the white noise startle stimulus of the ASR test.

Next, we examined social behavior in $\operatorname{Drd} 2^{\text {Pet1-CKO }}$ mice using the three-chambered test of sociability (Moy et al., 2004) that measures preference to investigate a social stimulus (a novel "stranger" mouse inside a holder) as compared with an object (an empty holder). Drd2 Pet1-CKO mice showed no alterations in sociability compared with controls and both control and Drd2 ${ }^{\text {Pet1-CKO }}$ spent significantly more time investigating the stranger than the object (Fig. 5A,B). Females of both genotypes displayed preference toward the social stimuli only for the first $5 \mathrm{~min}$ of the assay (Fig. 5B, white bars), while males displayed this preference throughout the 10-min assay. Similar sex differences in sustained preference for the social stimulus have been described in C57BL/6J mice (Netser et al., 2017).

We assayed intermale, territorial aggression in a separate cohort of mice using a resident-intruder assay. Females were not tested, as they have been shown to display low or no aggression in most forms of this assay (Palanza, 2001; Lonstein and Gammie, 2002). We observed no statistically significant difference in number of attack bites delivered to the intruder mouse by Drd2 ${ }^{\text {Pet1-CKO }}$ males $(n=26)$ compared with number of attack bites delivered to the intruder by controls $(n=24$; Drd2 ${ }^{\text {Pet } 1-C K O}: 4.07 \pm 1.50$ bites, controls: $1.77 \pm 0.39$ bites, $p=0.6649$, Mann-Whitney test; Fig. $5 C$ ) noting, however, that four Drd2 $2^{\text {Pet1-CKO }}$ males displayed high levels of aggression.

To assay social dominance, we performed the tube test, which has relevance in females as well as males (Lindzey et al., 1961; van den Berg et al., 2015; Zhou et al., 2017). Two mice are simultaneously released into opposite ends of a clear tube of sufficiently narrow diameter that prevents mice from passing by each other and instead requires that one back out for the other, more dominant "winning" mouse, to move forward (Fig. 5D). Drd2 ${ }^{\text {Pet1-CKO }}$ males won a higher percentage of trials against non-sibling, weight-matched, and genetic background-matched opponent males (shown as percent of trials won, Drd2 $2^{\text {Pet1-CKO: }} 65.83 \pm 9 \%, n=24$; controls: $34.17 \pm 9 \%, n=24 ; p=0.0065$, Mann-Whitney test; Fig. 5E). By contrast, we observed no difference in percent of trials won by female $D r d 2^{P e t 1-C K O}$ mice as compared with female sibling controls (Drd2 ${ }^{\text {Pet1-CKO }}$ : $48.7 \pm 8 \%, n=23$; controls $51.3 \pm 8 \%, n=23 ; p=0.8123$, Mann-Whitney test; Fig. $5 E)$.

\section{Drd2-Pet1 neurons in males versus females exhibit differences in candidate molecular and biophysical properties but not in cell number}

Given these sex-specific differences in behaviors observed in Drd2 ${ }^{\text {Pet1-CKO }}$ mice, next we looked for sex-specific differences in Drd2-Pet1 cellular properties, beginning with cell number. Analyzing triple transgenic Drd2-Cre; Pet1-Flpe; RC-FrePe males versus females, we found no difference in number of GFP ${ }^{+}$Drd2-Pet1 neurons per brain (males: $410.40 \pm 55.30$ cells/brain, females: $313 \pm 87.52$ cells/brain, $p=0.4304$, unpaired $t$ test; Fig. $6 A$ ). Further, in both males and females, Drd2-Pet1 neurons distributed as expected across the rostral-caudal and medial-lateral axis of the DR.

To understand whether gene expression might differ between male and female Drd2-Pet1 neurons, we examined single-cell RNA sequencing data previously analyzed for expression of serotonergic pathway genes as validation that Drd2-Pet1 cells were indeed serotonergic (Niederkofler et al., 2016). Comparison across sex, albeit 
A

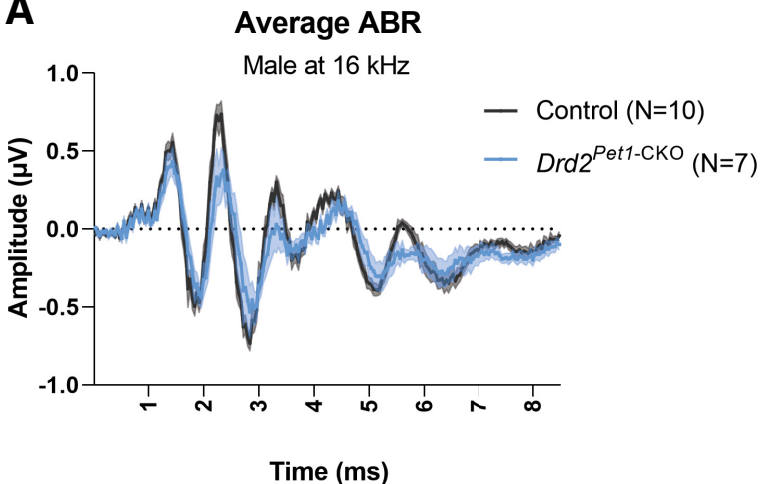

C

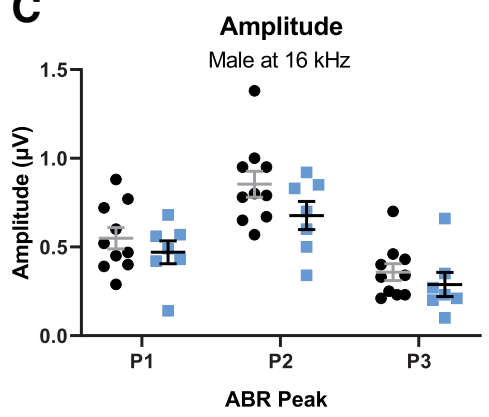

$\mathbf{F}$

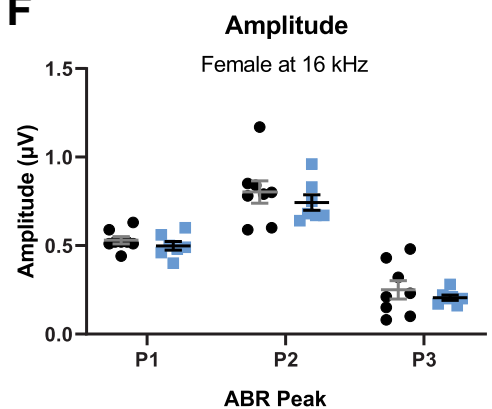

D

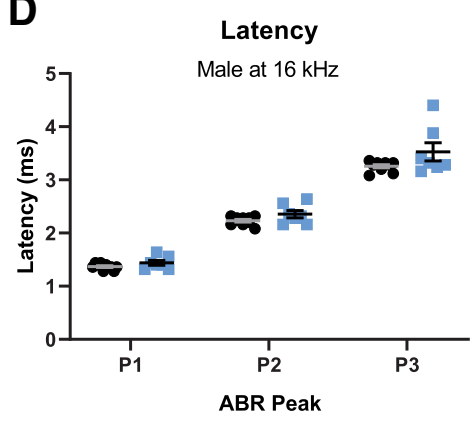

G

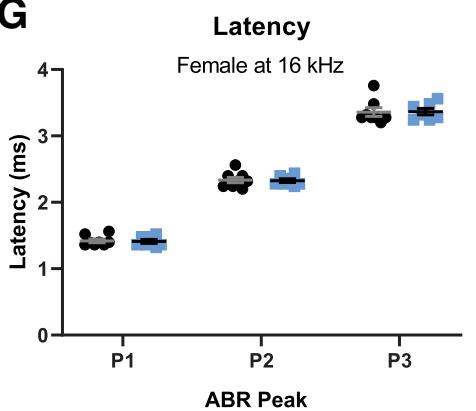

Average ABR

Female at $16 \mathrm{kHz}$

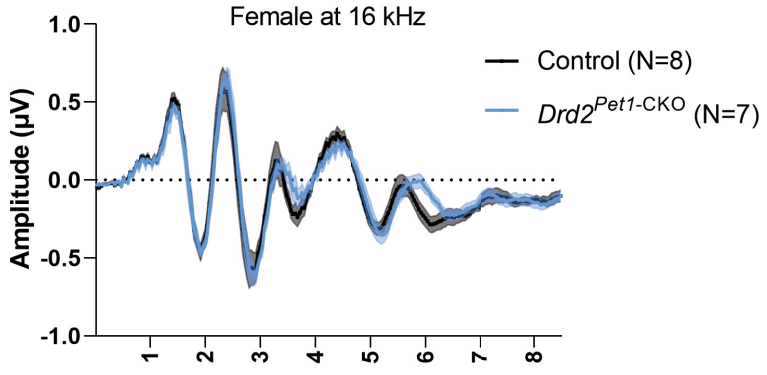

Time (ms)
E

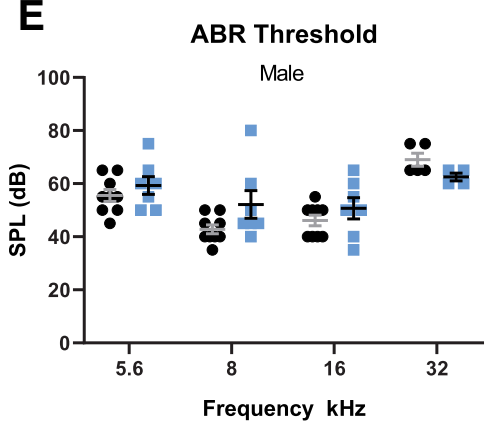

H

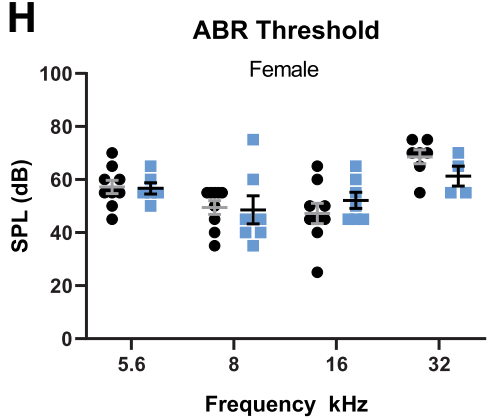

Figure 4. $\operatorname{Drd} 2^{\text {Pet1-CKO }}$ mice show normal auditory responses. $\boldsymbol{A}, \boldsymbol{B}$, Average ABR waveforms at $16 \mathrm{kHz}$ for $(\boldsymbol{A})$ control $(\mathrm{black}, n=10)$ and $\operatorname{Drd} 2^{\text {Pet1-CKO }}$ (blue, $n=7$ ) males and $(\boldsymbol{B})$ for control (black, $n=8$ ) and Drd2 ${ }^{\text {Pet1-CKO }}$ (blue, $n=7$ ) females. Average is shown by darker lines and shaded area shows SEM. C, $\boldsymbol{F}$, ABR amplitudes for control (black) and Drd2 ${ }^{\text {Pet1-CKO }}$ (blue; $\left.\boldsymbol{C}\right)$ male and $(\boldsymbol{F})$ female

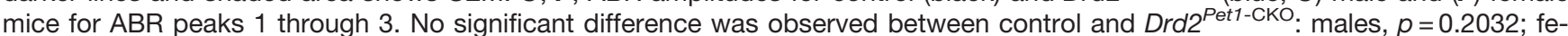
males, $p=0.1387$, two-way ANOVA. $\boldsymbol{D}, \boldsymbol{F}$, Latencies for control (black) and Drd2 ${ }^{\text {Pet1-CKO }}$ (blue; $\boldsymbol{D}$ ) male and (G) female mice for ABR peaks 1 through 3 . No significant difference was observed between control and Drd2 ${ }^{\text {Pet } 1-\mathrm{CKO}}$ : males, $p=0.0804 ;$ females, $p=0.9430$, two-way ANOVA. Amplitudes and latencies shown at 80-dB SPL. $\boldsymbol{E}, \boldsymbol{H}, \mathrm{ABR}$ thresholds for control (black) and Drd2 ${ }^{\text {Pet1-CKO }}$ (blue; $\boldsymbol{E})$ male and $(\boldsymbol{H})$ female mice across frequencies tested $(5.6,8,16$, and $32 \mathrm{kHz}$ ). No significant difference was observed between control and $D r d 2^{\text {Pet1-CKO }}$ mice, $p>0.05$ at all frequencies, unpaired $t$ test.

lacking statistical significance given the small sample size, highlighted four genes for further evaluation, Drd2, Dmd (encoding Dystrophin, a component of protein scaffolds in the CNS; Perronnet and Vaillend, 2010), Gad2 (encoding glutamate decarboxylase 2 involved in catalyzing the production of the neurotransmitter GABA), and Serpini1 (encoding the serine protease Neuroserpin, important for synapse formation and plasticity; Galliciotti and Sonderegger, 2006). Quantitative in situ mRNA detection using dual FISH with immunodetection on tissue sections from Drd2-Cre;Pet1-Flpe;RC-FrePe mice revealed greater abundance of average Gad2 transcripts (puncta) per cell in males versus females [Gad2:
$20.46 \pm 2.243$ in males $(n=5)$ vs $12.20 \pm 2.427$ in females $(n=5), p=0.0370$, unpaired $t$ test; Fig. $6 D$ ]. There was no difference in the percentage of Drd2-Pet1 neurons expressing Gad2 in male versus female mice (Fig. $6 E)$. No difference in soma size (GFP-stained cell body) was observed between males and females suggesting that transcript differences were not because of larger soma volume measured (Fig. 6C). No significant differences in mRNA abundance were observed between males and females for Dmd, Drd2, or Serpini1 (see Table 2).

As a first step toward understanding whether sex-specific gene expression differences observed in wild-type 
A

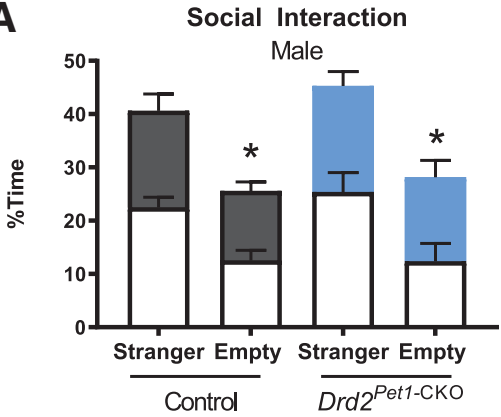

B

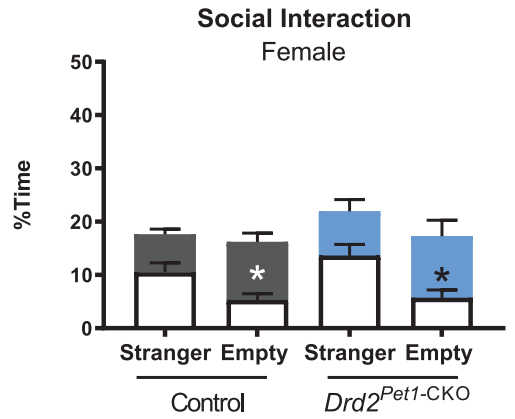

C

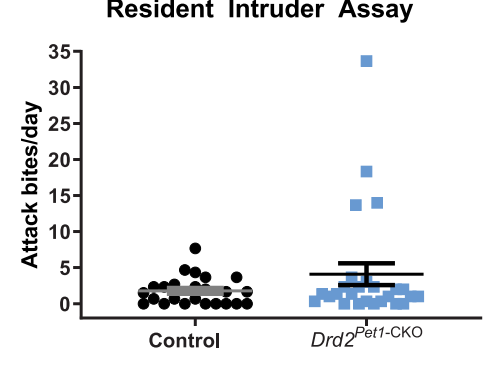

D

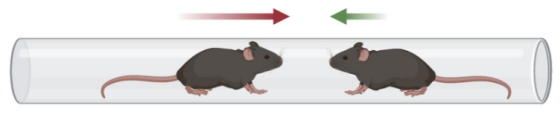

5 trials per same sex pair
E
Tube Test of Social Dominance

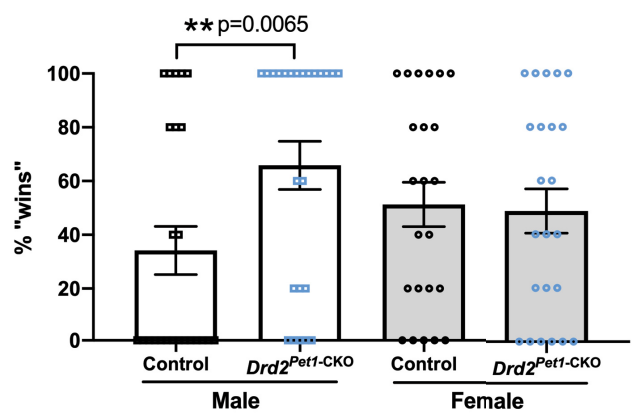

Figure 5. $\operatorname{Drd} 2^{\text {Pet1-CKO }}$ males, but not females, display increased social dominance. $\boldsymbol{A}, \boldsymbol{B}$, Three chambered social interaction assay. No significant difference in time spent investigating a stranger mouse or an empty holder for $(\boldsymbol{A})$ males $(n=8$ controls compared with 6 Drd2 $2^{\text {Pet1-CKO }}, p=0.541$, unpaired $t$ test) and $(\boldsymbol{B})$ females $\left(n=7\right.$ controls compared with $n=5$ Drd2 ${ }^{\text {Pet } 1 \text {-CKO }}, p=0.358$, unpaired $t$ test). Investigation time is binned into 5-min intervals where white bars indicate first 5 min of assay and colored bars indicate last 5 min of assay. As expected, mice of both genotypes spent significantly less time investigating the empty holder than the stranger mouse noting that females of both genotypes only did so during the first 5 min of the assay. C, Resident intruder assay of aggression. No significant difference in the average attack bites per day delivered to a Swiss Webster intruder mouse was observed between $\operatorname{Drd} 2^{\text {Pet1-CKO }}$ males $(n=26,4.07 \pm 1.50$ bites) aggression levels were not significantly different from controls $(n=24$, $1.77 \pm 0.39$ bites; Mann-Whitney, two-tailed, $U=289.5, p=0.6649$ ). $\boldsymbol{D}$, Schematic of tube test (for details of assay, see Materials and Methods). Schematic created with BioRender. $\boldsymbol{E}$, Drd2 ${ }^{\text {Pet1-CKO }}$ males $(n=24)$ demonstrate more dominance behavior than controls $(n=24)$ as they displayed increased winning in the tube test (controls: $34.17 \pm 9 \%$ wins, Drd2 Pet1-CKO: $65.83 \pm 9 \%$ wins, $p=0.0065$, Mann-Whitney, two-tailed, $U=166)$. Female Drd2 ${ }^{\text {Pet1-CKO }}(n=23)$ showed no difference in social dominance compared with controls $\left(n=23\right.$; controls: $51.3 \pm 8 \%$, Drd2 ${ }^{\text {Pet1-CKO: }} 48.7 \pm 8 \%$ wins, $p=0.8123$ Mann-Whitney, two-tailed, $U=253$ ).

mice persist or are altered in Drd2 $2^{\text {Pet1-CKO }}$ mice, we assessed Gad2 transcript levels in Drd2 ${ }^{\text {Pet1-CKO }}$ cells. In these cells, the floxed exon 2 of Drd2 is excised by Cre recombination. Therefore, to identify mutant Drd2 mRNA and thus the mutant Drd2 ${ }^{\text {Pet1-CKO }}$ cells, we used a multiprobe strategy involving one probe to intact downstream exons 7 and 8 (referred to here as Drd2-E7/8), another to exon 2 (referred to as Drd2-E2), and another to either cre or Pet1. We examined expression in the DR region most enriched with Drd2-Pet1 neurons. We found Drd2-E7/8+ puncta in Pet1 + cells in both controls and Drd2 Pet1-CKO mice, whereas Drd2-E2 + puncta were detectable in control tissue but greatly reduced in Drd2 $2^{\text {Pet1-CKO }}$ as expected given the efficiency of Cre-mediated gene deletion (Fig. 7A; see Drd2-E2 quantification in Fig. 1E). Drd2-E7/8 puncta were detected in $35.97 \pm 2.403 \%$ of Pet $1+$ cells in control mice $(n=6)$ compared with $36.53 \pm 3.621 \%$ of Pet1 + cells in Drd2 ${ }^{\text {Pet1-CKO }}$ mice $(n=6 ; p=0.8998$, unpaired $t$ test; Fig. 7B). Similarly, in a separate experiment using an in situ probe to cre mRNA, 34.91 $\pm 2.238 \%$ of cre + cells expressed Drd2-E7/8 ( $n=10$ mice, one-way ANOVA compared with Pet1 control and Drd2 ${ }^{\text {Pet1-CKO }}$ cell expression, $p=0.9051$; Fig. 7B). Next, we analyzed Gad2 mRNA transcript levels in Drd2 ${ }^{\text {Pet1-CKO }}$ cells (dual Drd2$\mathrm{E} 7 / 8+$ and cre + cells) in the DR (Fig. 7C). In males, we observed $87.44 \pm 3.034 \%$ of Drd2 ${ }^{\text {Pet1-CKO }}$ cells were Gad2+, while this percentage was $75.76 \pm 0.5862 \%$ in females $(p=0.0157$, unpaired $t$ test; Fig. 7D). In these Drd2 ${ }^{\text {Pet } 1 \text {-CKO }}$ cells, there were $14.25 \pm 1.325$ transcripts per cell in males and 10.13 \pm 2.074 transcripts per cell in females $(p=0.1151$, unpaired $t$ test; Fig. $7 E$ ). Because of the tightly packed distribution of cells in the DR, puncta were measured only within cre+ DAPI-stained nuclei to ensure puncta were not assigned to more than one cell. The area of nuclei did not differ between males $\left(114.9 \pm 3.030 \mu^{2}\right)$ and females $\left(110.9 \pm 1.768 \mu \mathrm{m}^{2}\right.$, $p=0.3497$, unpaired $t$ test; Fig. 7F). Thus, in Drd2 ${ }^{\text {Pet } 1 \text {-CKO }}$ males as compared with Drd2 ${ }^{\text {Pet1-CKO }}$ females, a greater percentage of the Drd2-Pet1 cells harbored Gad2 transcripts; of these Gad2-expressing cells, however, transcript levels were not significantly different between males versus female Drd $2^{\text {Pet1-CKO }}$ mice.

To explore potential sex differences in electrophysiological properties characterizing Drd2-Pet1 neurons, we 
A Drd2-Cre;Pet1-Flpe;RC-FrePe
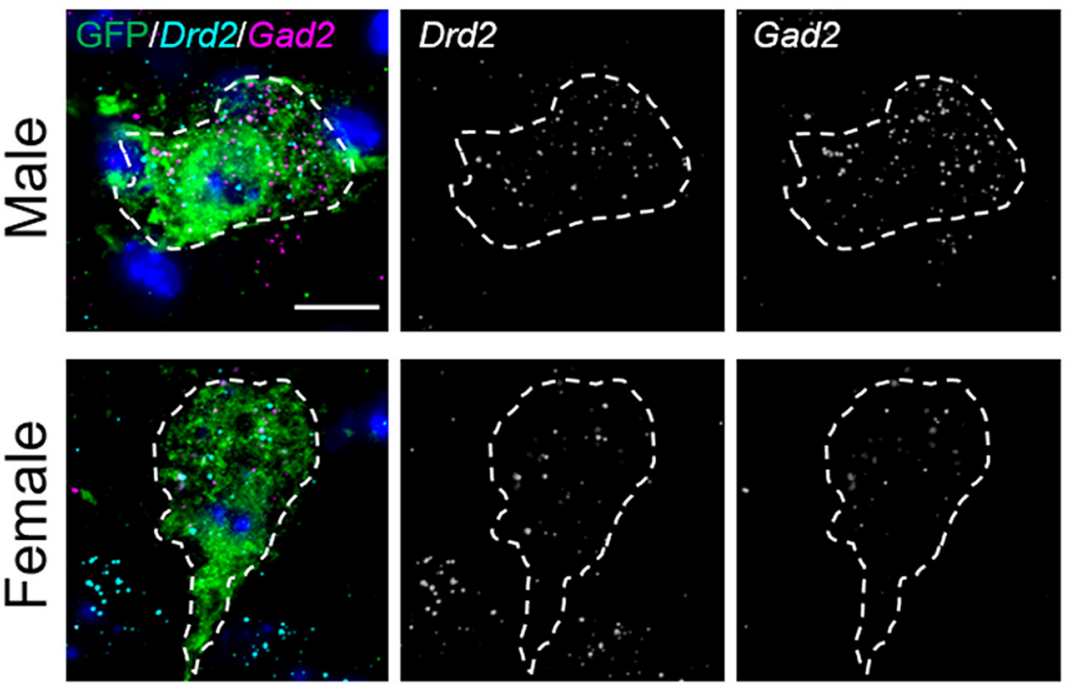

Sex-specific gene expression in Drd2-Pet1 neurons

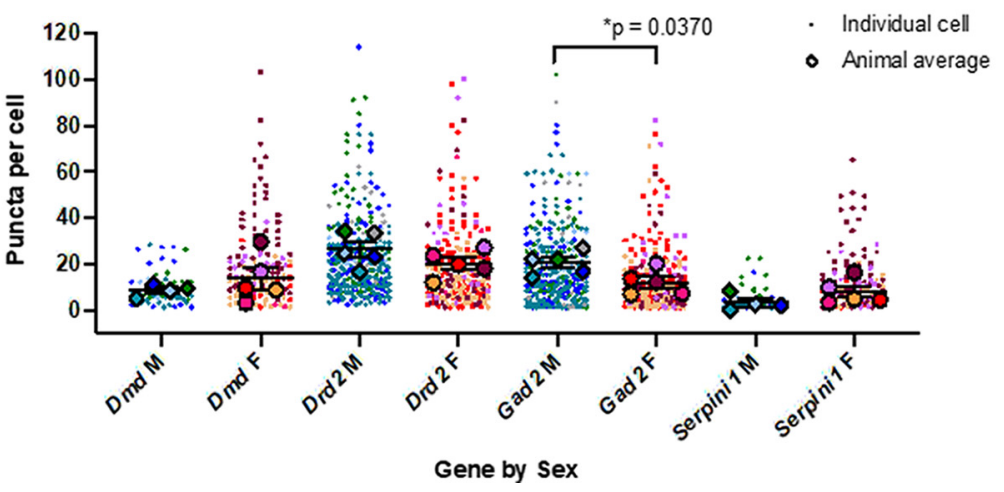

B Drd2-Pet1 Neuron Count
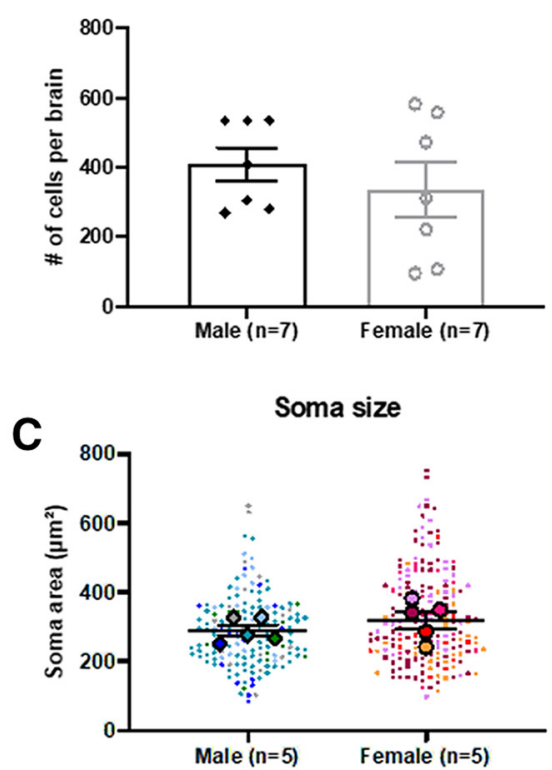

E Gad2 expression in Drd2-Pet1

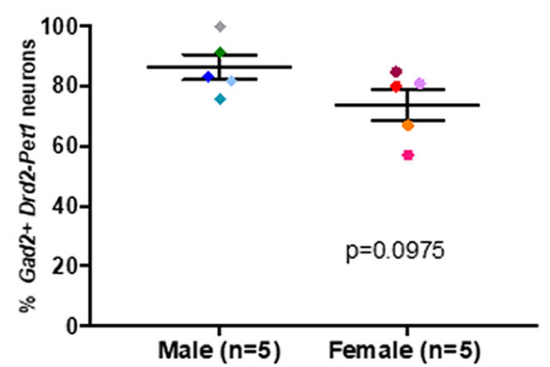

Figure 6. Sex-specific transcript level differences in Drd2-Pet1 neurons. A, Dual immunohistochemistry and FISH depicting green GFP + Drd2-Pet1 neurons along with transcript puncta in male (top) and female (bottom) brain sections from Drd2-Cre;Pet1-Flpe; $R C$-FrePe mice. Drd2 (cyan) and Gad2 (magenta) expression shown together and separately in gray scale. Scale bar: $10 \mu \mathrm{m}$. B, Number of Drd2-Pet1 neurons (GFP-positive cells in Drd2-Cre;Pet1-Flpe;RC-FrePE mice) per animal in males (black diamonds, $n=7$ ) and females (open gray circles, $n=7$ ) is not significantly different. Males: $410.40 \pm 55.30$ cells/brain, females: $313 \pm 87.52$ cells/brain, $p=0.4336$, unpaired $t$ test. $\boldsymbol{C}$, Drd2-Pet1 neuron soma size (GFP + cell body) does not differ in males ( $n=5$ males) versus females ( $n=5$ females), $p=0.3372$, unpaired $t$ test. $\boldsymbol{D}$, Number of FISH mRNA puncta per cell in males versus females. Male cells have significantly more Gad2 puncta than female cells [20.46 \pm 2.243 in males $(n=5)$ vs $12.20 \pm 2.427$ in females $(n=5), p=0.0370$, unpaired $t$ test]. $\boldsymbol{E}, 86.47 \pm 4.181 \%$ of male Drd2-Pet1 cells express Gad2 versus female $74.00 \pm 5.168 \%$ in female cells, $p=0.0975$, unpaired $t$ test. Error bars indicate SEM throughout. For $\boldsymbol{C}, \boldsymbol{D}$, larger symbols outlined in black represent animal averages used for statistical analysis, smaller symbols represent individual cells, matched in color to the average.

conducted whole-cell recordings from GFP-labeled Drd2Pet1 neurons in brain slices from triple transgenic Drd2$\mathrm{Cre}$;Pet1-Flpe;RC-FrePe males and females. Examination of cell membrane characteristics revealed no sex differences in resting membrane potential (AP; Fig. $8 A$ ) or resistance (Fig. 8B). Analyses of AP characteristics revealed an increase in AP duration (Fig. $8 E$ ) in male Drd2-Pet1 cells as compared with female $(2.847 \pm 0.155 \mathrm{~ms}, n=19$ cells vs $2.54 \pm 0.094 \mathrm{~ms}, n=44$ cells, respectively, $p=0.0275$, unpaired $t$ test], but no differences in AP threshold (Fig. $8 C$ ), amplitude (Fig. $8 D$ ), or afterhyperpolarization (AHP) amplitude (Fig. 8F).

\section{Differing covariance in axonal collateral densities from Drd2-Pet1 neurons directed to auditory targets in males versus females}

As a first step in exploring sex differences in Drd2-Pet1 neuron circuitry that may underlie the sex-specific behavioral phenotypes in Drd2 ${ }^{\text {Pet1-CKO }}$ mice, we compared relative innervation density to brain regions involved in sensory processing and social behavior in male and female mice. Boutons from Drd2-Pet1 neurons were selectively marked with a Synaptophysin-GFP fusion protein using triple transgenic Drd2-Cre;Pet1-Flpe;RC-FPsit mice (Fig. 9A,B; Niederkofler et al., 2016). At P90, the same age 
A
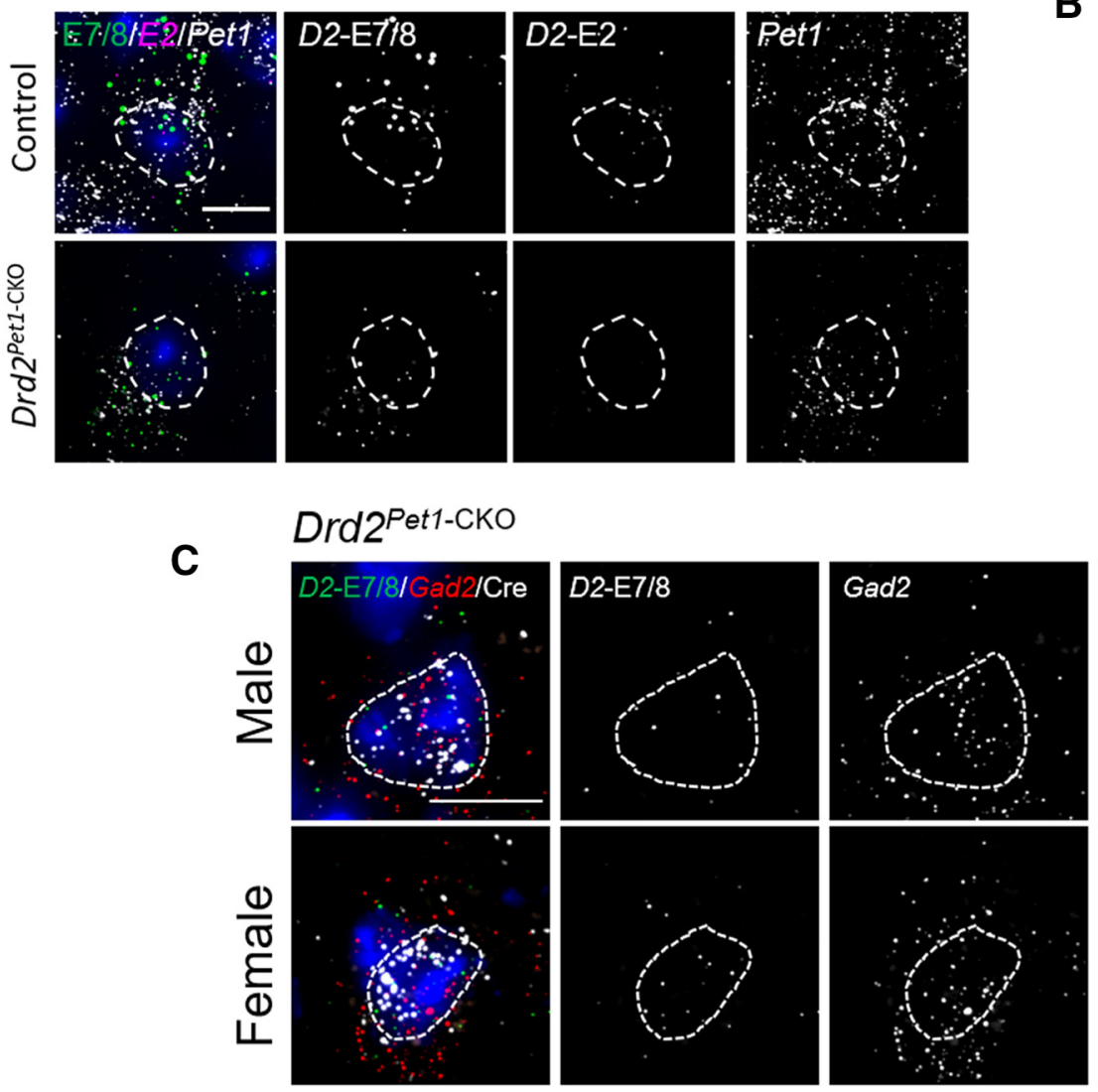

E
D

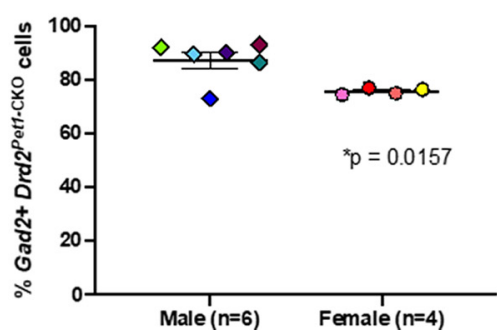

Gad2

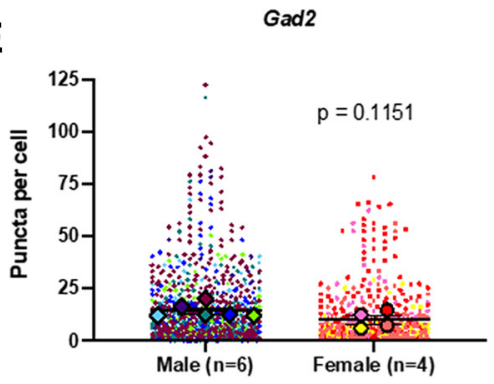

\begin{abstract}
E
\end{abstract}
B

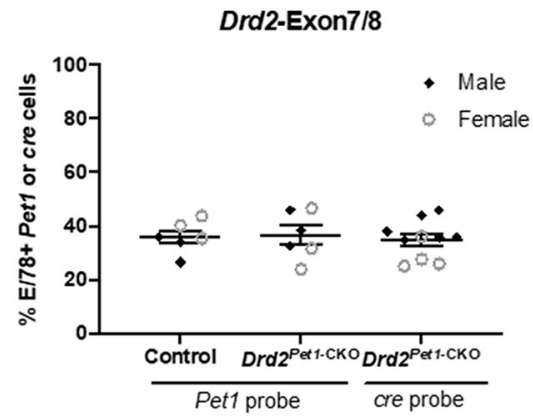

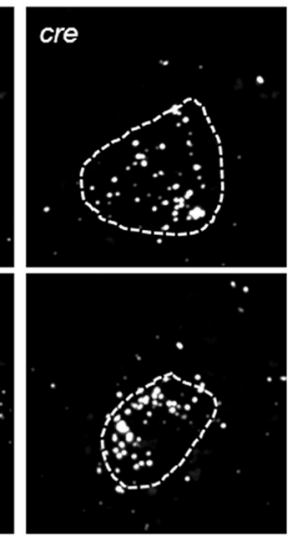

$\mathbf{F}$

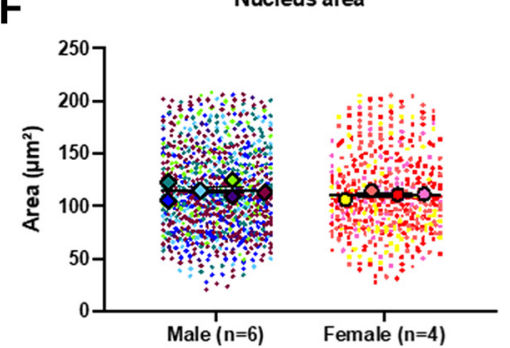

Figure 7. Gad2 expression in Drd2 ${ }^{\text {Pet1-CKO }}$ cells. A, FISH with probes to Drd2 exon 7/8 (D2-E7/8, green) and Drd2 exon 2 (D2-E2, magenta) in Pet1 (white) cells in control (top) and Drd2 ${ }^{\text {Pet1-CKO }}$ (bottom) DR tissue. D2-E7/8, D2-E2, and Pet1 expression shown together and separately in gray scale. B, Percent of Pet1 + cells (left and middle) with Drd2-Exon7/8 expression in control (35.97 \pm $2.403 \%, n=6)$ and $\operatorname{Drd} 2^{\text {Pet1-CKO }}(36.53 \pm 3.621 \%, n=6), p=0.8998$, unpaired $t$ test. Data also shown for percent of cre cells (right) with Drd2-Exon7/8, $34.91 \pm 2.238 \%$, compared with Pet1 probe control and Drd2 ${ }^{\text {Pet1-CKO }} p=0.9051$, one-way ANOVA. Males, black diamonds, females, open gray circles. C, FISH showing cre+ Drd2 ${ }^{\text {Pet1-CKO }}$ cells (white) with Drd2-Exon7/8 (green) and Gad2 (red) in male (top) and female (bottom) in the DR nucleus. Drd2-Exon7/8, Gad2, and cre are shown together and separately in gray scale. Scale bar: $10 \mu \mathrm{m}$. D. A larger percentage of male Drd2 ${ }^{\text {Pet1-CKO }}$ cells $(87.44 \pm 3.034 \%)$ express Gad2 versus female Drd2 $2^{\text {Pet } 1 \text {-CKO }}$ cells $(75.76 \pm$ $0.5862 \%),{ }^{*} p=0.0157$, unpaired $t$ test. $\boldsymbol{E}$, Number of Gad2 mRNA puncta per cell in Drd2 ${ }^{\text {Pet1-CKO }}$ cells in males $(n=6)$ versus females $(n=4)$. Male cells have $14.25 \pm 1.325$ Gad2 puncta per cell compared with $10.13 \pm 2.074$ in female cells, $p=0.1151$, unpaired $t$ test. $\boldsymbol{F}$, Drd2 ${ }^{\text {Pet } 1-C K O}$ nucleus size (area used to quantify puncta levels) does not differ in males ( $n=6$ males) versus females $(n=4$ females), $p=0.3497$, unpaired $t$ test. Error bars indicate SEM throughout. For $\boldsymbol{E}, \boldsymbol{F}$, larger symbols outlined in black represent animal averages used for statistical analysis, smaller symbols represent individual cells, matched in color to the average.

at which the behavioral assays were conducted, we collected brain tissue and quantified projections to the cochlear nucleus complex (CNC), superior olivary complex (SOC), lateral lemniscus (LL), inferior colliculus (IC), caudal pontine reticular nucleus (PNC; critical for ASR; Davis et al., 1982), dorsal lateral geniculate nucleus (dLGN), mPOA, medial habenula $(\mathrm{mHb})$, periaqueductal gray (PAG), and dorsal paragigantocellular nucleus (DPGi; shown as percentage of target area occupied by projections; Fig. 9C). We observed no significant sex differences in the cohort average for absolute innervation density to each of these 10 brain regions. However, because we observed considerable interanimal variability in bouton densities at targets, we next explored correlation of innervation density across brain regions 

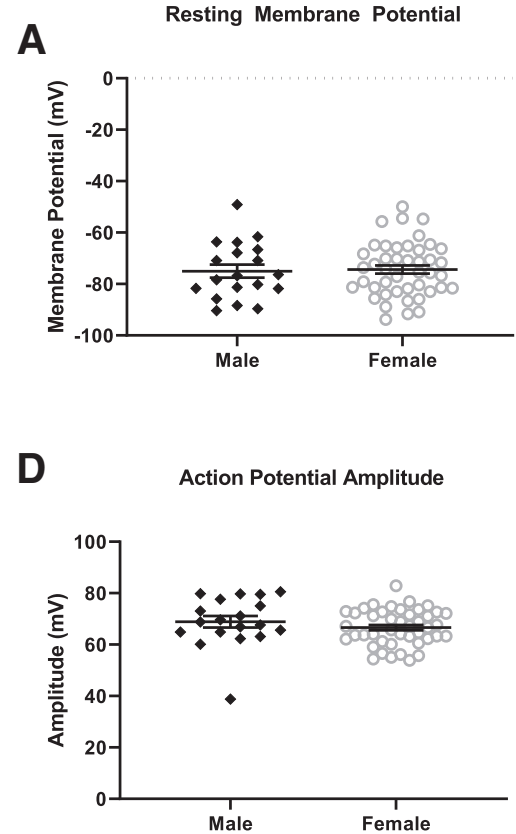

Figure 8. Drd2-Pet1 neuron electrophysiological properties in male versus female mice. Membrane and AP characteristics were analyzed in GFP-marked Drd2-Pet1 male and female neurons using whole-cell patch-clamp electrophysiology in acute brain slices from triple transgenic Drd2-Cre;Pet1-Flpe;RC-FrePe mice. Membrane potential $(\boldsymbol{A})$, membrane resistance $(\boldsymbol{B})$, AP threshold $(\boldsymbol{C})$, AP amplitude $(\boldsymbol{D})$, and AHP amplitude $(\boldsymbol{F})$ do not differ in male $(n=19)$ or female $(n=44)$ Drd2-Pet1 neurons while $(\boldsymbol{E})$ male Drd2-Pet1 neurons had a significantly longer $(2.847 \pm 0.155 \mathrm{~ms}, n=19$ cells) AP duration than in females $(2.54 \pm 0.094 \mathrm{~ms}, n=44$ cells, $p=0.0275$, unpaired $t$ test).

(Weissbourd et al., 2014). Using pairwise correlations between auditory brain regions (Fig. 9D), we constructed a correlation matrix that shows positively correlated regions in green and negatively correlated regions in black (Fig. 9E). This visualization reveals that most auditory brain regions are positively correlated in males (SOC and LL, Pearson's $r=0.89$ ) with only the $\mathrm{LL}$ and cochlear nucleus being slightly negatively correlated (Pearson's $r=-0.28$ ). Interestingly, a greater number of innervated regions were negatively correlated in females, including the CNC with both the SOC and the IC ( $r=-0.68$ and $r=-0.75$, respectively), as well as PNC and IC $(r=-0.67)$. The innervation of the PNC and SOC was significantly negatively correlated $(r=-0.85, p=0.033$, twotailed test). Further, we expanded analyses to include the dLGN, a region critical for visually-cued potentiation of the acoustic startle (Tischler and Davis, 1983), and found that in females innervation of the dLGN was not strongly correlated with innervation of auditory brain regions, while in males this dLGN innervation was highly negatively correlated with both the SOC ( $r=-0.91, p=0.033$, two-tailed test) and the IC ( $r=$ $-0.91, p=0.034$, two-tailed test), indicating that Drd2-Pet1 neuron circuitry may be set up to modulate multisensory information differently in males compared with females.

\section{GABA and 5-HT in Drd2-Pet1 neurons}

Given detection of Gad2 mRNA in Drd2-Pet1 neurons, we probed for GABA versus $5-\mathrm{HT}$ immunopositivity in cell soma versus axonal boutons in males versus females. Punctate GABA immunostaining was indeed detectable in some Drd2-Pet1 neuron soma (Fig. 10A) in both males and females. Yet, in all target brain regions examined,
GABA was undetectable in the GFP-marked Drd2-Pet1 boutons. Shown are representative images from the SOC (Fig. 10B) and IC (Fig. 10C), noting a GABA-positive cell body in the IC (boxed) and GABA-positive staining in the corpus callosum serving as a positive control for GABA immunodetection (Fig. 10D). By contrast, 5-HT immunostaining in Drd2-Pet1 boutons was readily detectable (representative images from the SOC and IC; Fig. 9B).

\section{Discussion}

\section{Strategy}

We hypothesized that loss of $D r d 2$ gene expression and associated DRD2 signaling normally observed in certain DR Pet $1^{+}$serotonergic neurons (Drd2-Pet1 neurons) could impair sensory, social, and/or defensive behaviors. We used the transgenic driver ePet-cre to delete functionally critical $D r d 2$ gene sequences selectively in serotonergic neurons, thereby abolishing transcript and DRD2 protein function, which would normally initiate in Pet1 cells during adolescence. We validated these Drd2 $2^{\text {Pet1-CKO }}$ mice and examined behavioral responses. Further, we explored Drd2Pet1 neurons themselves.

\section{Main findings}

Key findings include the following. (1) Sex-specific behavioral alterations were observed in Drd2 ${ }^{\text {Pet1-CKO }}$ mice. Females showed a dramatic diminution in the protective, defensive ASR as compared with $D r d 2^{\text {floxfflox }}$ controls, while no differences were observed in males. (2) Drd2 Pet1-CKO males, but not females, showed increased winning in the 
A

RC-FPSit

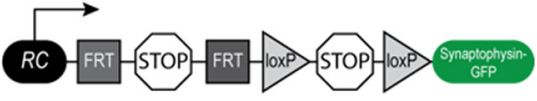

C

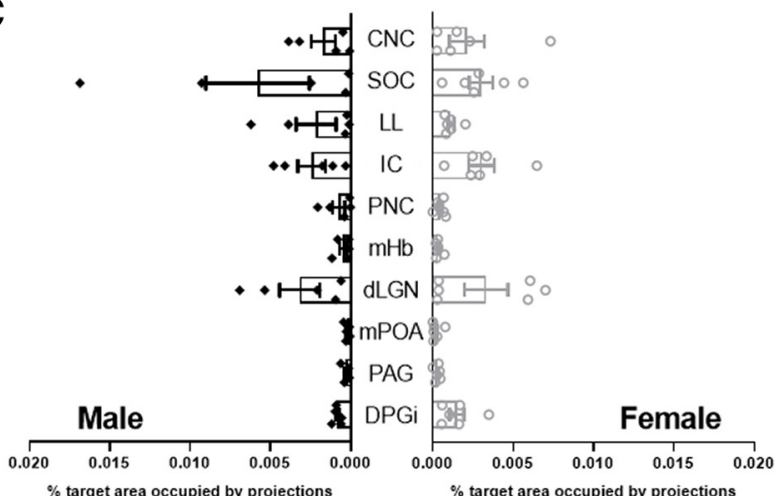

B
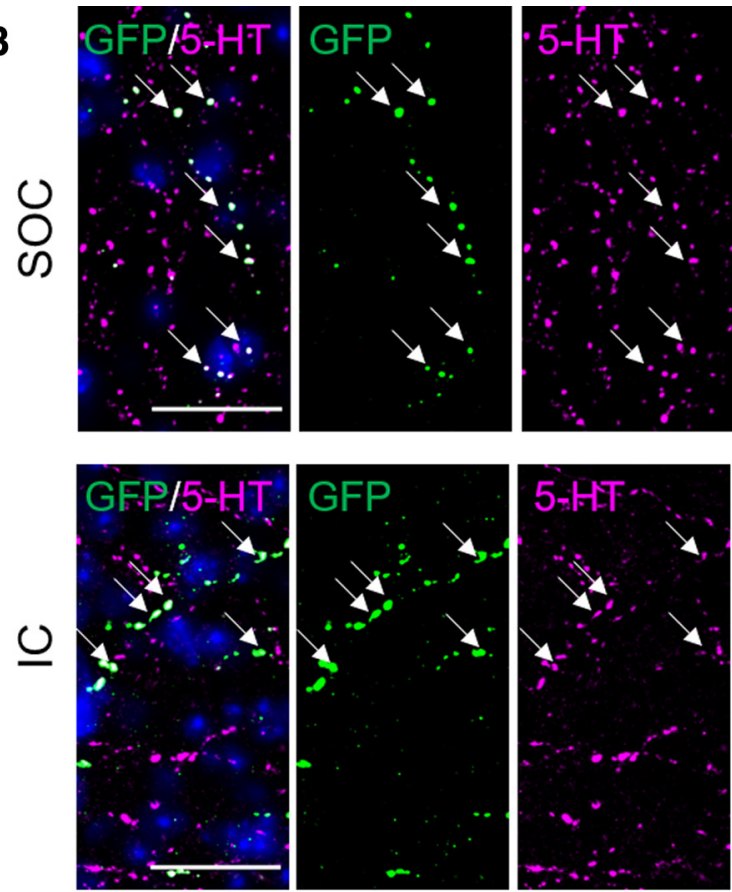

D

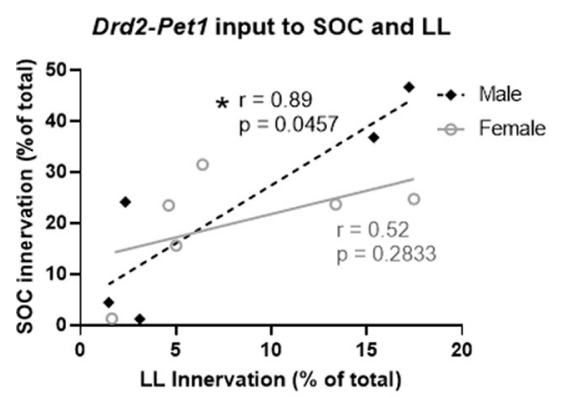

LL Innervation (\% of total)

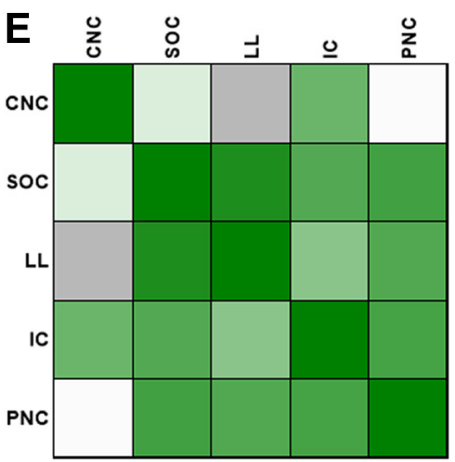

Male

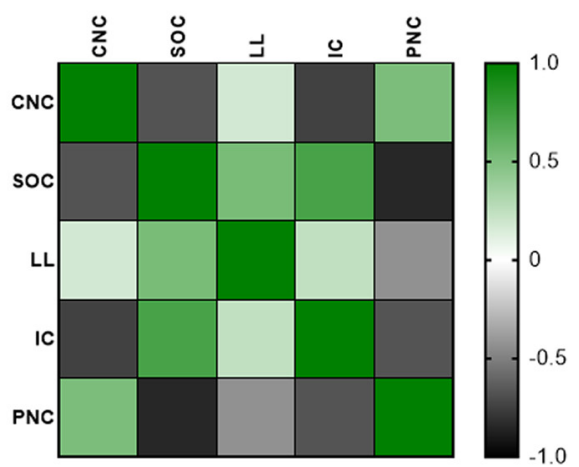

Female

Figure 9. Drd2-Pet1 neuron axon terminals target brain regions involved in sensory processing and defensive behavior in both male and female mice. $\boldsymbol{A}$, Intersectional genetic strategy: expression of Drd2-Cre and Pet1-Flpe transgenes results in dual recombination of intersectional allele, RC-FPSit, to label boutons of Drd2-Pet1 neurons with Synaptophysin-GFP. B, Representative images of Drd2-Pet1 boutons in the SOC and IC. GFP+ (green, marked with arrows) boutons co-localize with 5-HT (magenta) staining. DAPIstained nuclei shown in blue. Scale bar: $25 \mu \mathrm{m}$. $\boldsymbol{C}$, Quantification of the percent target area occupied by projections for all ten brain regions examined (for quantification protocol, see Materials and Methods). Target areas analyzed include brain regions involved in auditory processing and social behavior including the CNC, SOC, LL, IC, PNC, mHb, dLGN, mPOA, and PAG. The DPGi was also examined. No significant differences in projection area innervation were observed between males $(n=5)$ and females $(n=6)$. $\boldsymbol{D}$, Example graph showing correlation between innervation density of auditory brain regions differs in males compared with females. Each dot represents one animal. Values are shown as Pearson's correlation coefficient ( $r$ ), and * indicates $p<0.5$ in a two-tailed test. $\boldsymbol{E}$, Pairwise correlations shown for male and female innervation density in auditory brain regions. Heatmaps represent high correlation (green) and low correlation (black) between CNC, SOC, LL, IC, and PNC.

tube test of social dominance against sex-matched and age-matched controls. (3) No differences were observed in ABRs, in PPI of acoustic startle, locomotion, cognition, nor various affective behaviors. (4) No sex-specific differences were found in Drd2-Pet1 neuron number, soma distribution, nor in the set of efferent targets; however, within-animal correlations between efferent densities across target brain regions suggest differences by sex, thus hinting at sex-specific structural differences in Drd2-Pet1 neuronal circuitry. (5) Drd2-Pet1 cells in males as compared with females showed longer AP durations and higher levels of Gad2 transcripts (important for GABA synthesis); Drd2 ${ }^{\text {Pet1-CKO }}$ cells did not show a sex specific difference in Gad2 transcript levels, but the percentage of Drd2-Pet1 cells that were $\mathrm{Gad}^{+}$in Drd2 $2^{\text {Pet1-CKO }}$ males was slightly higher than in Drd2 ${ }^{\text {Pet1-CKO }}$ females. These findings, coupled with our prior work (Niederkofler et al., 2016) implicating Drd2-Pet1 neurons in setting levels of defensive aggressive and exploratory behaviors in male mice, suggest that Drd2-Pet1 neurons may serve as a specialized neuromodulatory interface whereby DRD2 
A
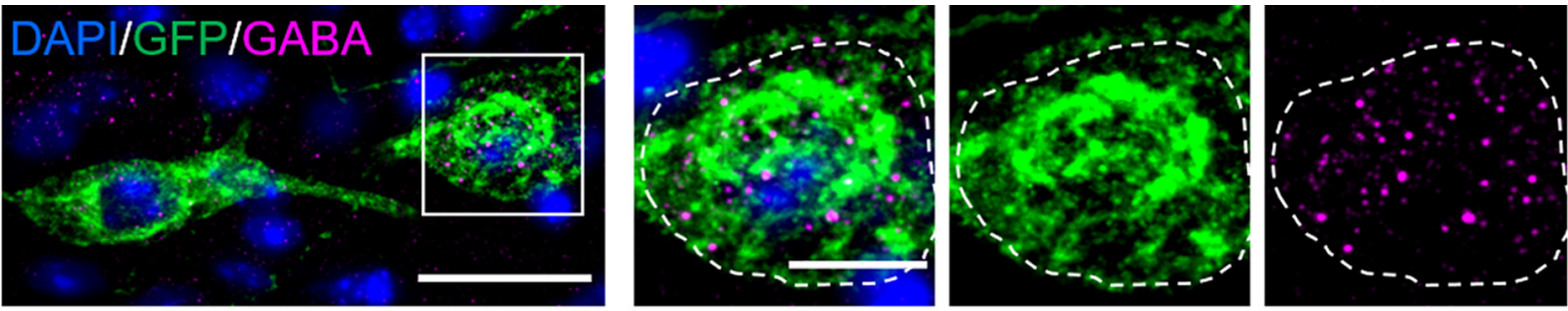

\section{옴}
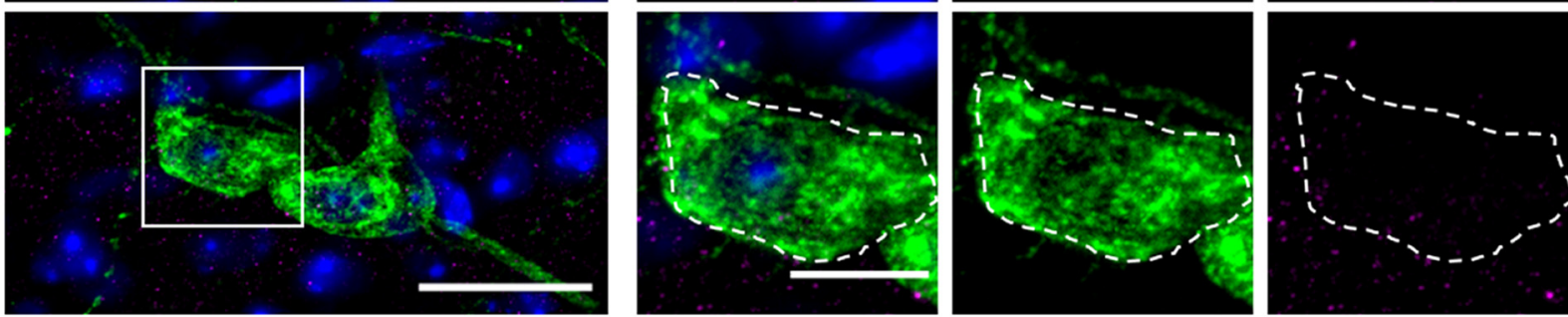

B
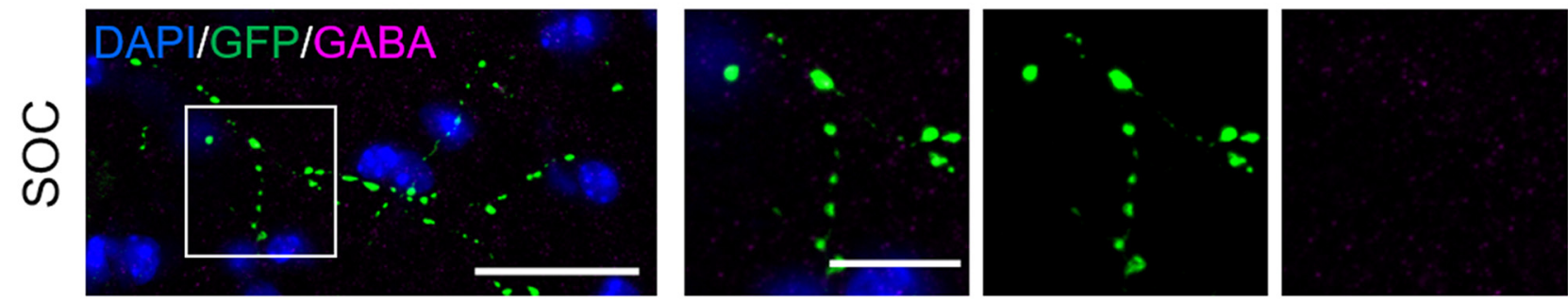

C
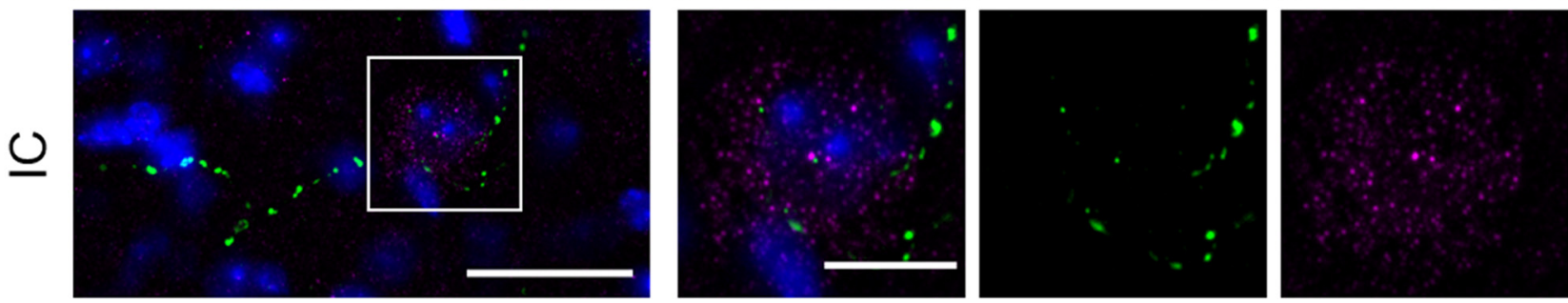

D
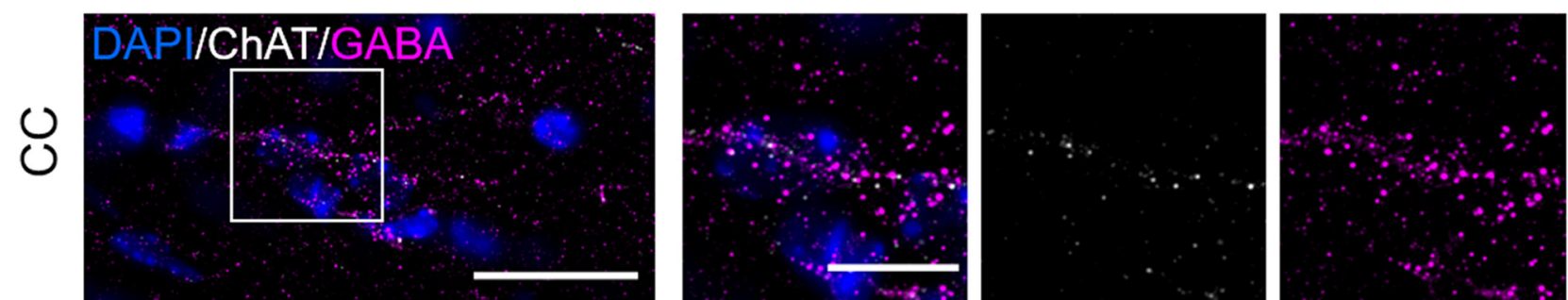

Figure 10. GABA immunoreactivity localizes to soma, but not axonal projections, of Drd2-Pet1 neurons. $\boldsymbol{A}$, GABA staining (magenta) co-localizes with many Drd2-Pet1 neuron soma (green GFP-positive cell bodies in Drd2-Cre;Pet1-Flpe;RC-FPSit mice) in the DR in a punctate manner (top), inset of boxed region showing neuron soma positive for GFP and GABA. Some Drd2-Pet1 neuron soma are immuno-negative for GABA (bottom). Dotted lines encircle GFP-positive cell body. $\boldsymbol{B}$, $\boldsymbol{C}$, No GFP-positive Drd2-Pet1 boutons (green) co-localize with GABA staining (magenta) in brain regions examined, shown here, representative images from SOC $(\boldsymbol{B})$ and IC $(\boldsymbol{C})$, noting a GABA-positive soma is visible in the image of the IC. $\boldsymbol{D}$, GABA-positive immunoreactivity in the corpus callosum demonstrating detection of GABA boutons. ChAT (white) staining was used throughout for anatomic localization. Scale bars: $25 \mu \mathrm{m}$ (left panel) and $10 \mu \mathrm{m}$ (inset). DAPI-stained nuclei shown in blue.

signaling alters serotonergic neuronal activity to shape defensive, protective, and dominance behaviors in a sex-specific manner.

\section{Protective ASR diminished in Drd2 ${ }^{\text {Pet1-CKO }}$ females}

Defensive posturing in millisecond response to abrupt noise, be it a predator or other potential hazard, is a crucial evolutionarily conserved protective mechanism. Loss or blunting of this reflex can result in life-threatening exposure, while excessive enhancement can drive unnecessary, debilitating responses that preclude normal functioning. Thus, "tuning" of the ASR setpoint to social and environmental circumstances is likely critical for species survival and well-being. The observed ASR attenuation in female $D r d 2^{P e t 1-C K O}$ mice suggests that Drd2-Pet1 neurons and the regulation of their activity cell autonomously by DRD2 comprises a critical 
modulatory node for ASR in females. Further, this node appears separate functionally from that involved in acoustic sensorimotor gating, given that acoustic PPI appeared intact in Drd2 ${ }^{\text {Pet } 1-C K O}$ females, and from hearing, given that $A B R s$ were indistinguishable from controls. Thus, DRD2 signaling in Drd2-Pet1 neurons forms a functional circuit node specialized in female mice to influence startle to acoustic stimuli.

In rats, reduction of 5-HT through synthesis inhibition increases ASR in females, but not males (Pettersson et al., 2016). Predicted reciprocally is that elevated 5-HT levels might blunt ASR in females. Relating this to our findings, it is possible that Drd2-Pet1 neurons are more excitable in the absence of DRD2-mediated inhibition, resulting in increased $5-\mathrm{HT}$ release, perhaps explaining the observed ASR blunting. In wild-type mice, this would predict that under conditions of DA elevation, for example through local DR DA neuron activity associated with arousal and vigilance (Cho et al., 2017), Drd2-Pet1 neuron activity would be inhibited, reducing $5-\mathrm{HT}$ release and thereby tuning a more sensitive ASR, conferring a protective advantage.

The ASR circuit follows from cochlea to CNC to PNC to spinal motoneurons (Davis et al., 1982; Koch et al., 1992), and receives inputs from auditory centers such as the SOC, IC, and SC (Lauer et al., 2017). Drd2-Pet1 neurons innervate each of these areas and the PNC, and thus may impart modulation at multiple levels.

\section{Tube test wins increased in Drd2 ${ }^{P e t 1-C K O}$ males}

The increased winning by $D r d 2^{P e t 1-C K O}$ males in the tube test suggests that loss of DRD2 results in an increase in or favoring of dominance behaviors, at least under these forced, one-on-one interaction conditions. We did not observe significant differences in levels of aggressive attack behaviors by $D r d 2^{\text {Pet1-CKO }}$ males in a resident-intruder assay. Together, these findings suggest that in wild-type mice, DRD2 signaling in Drd2-Pet1 neurons contributes to tempering certain dominance behaviors under particular conditions.

Understanding how the present results align with our prior work remains a pursuit. In earlier studies using a resident-intruder assay, we observed an increase in various aggressive behaviors in mice in which Drd2-Pet1 neurons were constitutively silenced, which suggested to us that Drd2-Pet1 neuron excitation and neurotransmitter release would normally temper such behaviors (i.e., favor nonconfrontational, even submissive behaviors). Because canonical DRD2 signaling is inhibitory and, as well, appears largely inhibitory in Drd2-Pet1 neurons in slice, we predicted that loss of DRD2 signaling would enhance Drd2Pet1 cell excitability and neurotransmitter release probability, and thus would suppress or at least not enhance dominance behaviors. Yet Drd2 ${ }^{\text {Pet1-CKO }}$ males exhibited enhanced winning in the tube test. Perhaps DRD2 signaling in Drd2-Pet1 neurons results in cellular activity changes that ultimately lead to a tempering of one-onone social dominance under some conditions, while extreme, constitutive Drd2-Pet1 neuron silencing is required to prompt the opposite, in the form of aggression escalation to an intruder. Indeed, other findings also support this notion that dominance by tube test does not necessarily correlate with aggression in a resident-intruder assay (Tammimäki et al., 2010). Differences might also be explained by whether the input conditions trigger Drd2Pet1 neurons to release 5-HT versus GABA, should the latter prove a capability, noting that Drd2-Pet1 cells express Gad2, albeit we were unable to show GABA in Drd2-Pet1 boutons, only their soma.

Interestingly, a subset of $\operatorname{Drd} 2^{\text {Pet1-CKO }}$ males (four out of 26) did display increased levels of aggressive behaviors

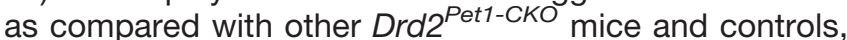
suggesting there may be other influencing variables, yet unknown. This is plausible given that mice deficient for the long isoform of DRD2 $\left(D_{2 L} R\right)$ are reported to show anxiety-like and depressive-like behaviors only following a stress-exposure paradigm (Shioda et al., 2019). Moreover, these stress-induced affective phenotypes in $D_{2 L} R$ knock-out mice were abrogated by driving $D_{2 L} R$ expression in DR Pet1 + serotonergic neurons (Shioda et al., 2019). Together these findings suggest that the behavioral role of Drd2 expression in Drd2-Pet1 neurons may be influenced by environmental factors.

\section{Sex-specific differences in Drd2-Pet1 neuron properties}

The observed sex-specific differences in Gad2 transcript levels in Drd2-Pet1 neurons may contribute to the sex-specific behavioral alterations exhibited by $\operatorname{Drd} 2^{\text {Pet1-CKO }}$ mice. Gad2 expression in Drd2-Pet1 neurons is in line with prior reports showing Gad2 expression more generally in the serotonergic DR (Nanopoulos et al., 1982; Calizo et al., 2011; Shikanai et al., 2012). It may be that Drd2-Pet1 neurons can release GABA as well as or instead of 5-HT under certain conditions or at particular targets. This capacity may differ in males versus females, given our observation that in males, Drd2-Pet1 neurons harbor higher levels of Gad2 mRNA. Interestingly, Drd2 ${ }^{\text {Pet1-CKO }}$ cells did not display this sex specific difference in Gad2 transcript, suggesting that Drd2 expression, or more broadly dopaminergic signaling in Drd2-Pet1 neurons, may affect Gad2 transcript levels. One potential model to be tested is if DRD2 signaling, in turn, alters levels of Gad2 expression to allow for neuronal release of GABA in addition to or instead of serotonin when behavioral or environmental conditions necessitate. Indeed, there is precedent for the differential usage of serotonin and glutamate by raphe serotonergic neurons (Liu et al., 2014; Kapoor et al., 2016; Sengupta et al., 2017; Wang et al., 2019), although GABAergic and serotonergic co-release has not been reported.

AP duration measured ex vivo was longer in male versus female Drd2-Pet1 cells; this may also confer neurotransmitter release properties that could contribute to behavioral differences. Additional studies are needed to determine how Drd2 ${ }^{\text {Pet1-CKO }}$ affects Drd2-Pet1 neuron electrophysiology, gene expression, or efferent targets. Such experiments may be achieved through crossing Drd2 ${ }^{\text {Pet1-CKO }}$ (ePet1Cre;Drd2 ${ }^{f / f}$ ) mice to Drd2-Flpo mice (The Jackson Laboratory strain \#034419 provided by Bernardo Sabatini) along with an intersectional reporter transgene which would 
allow for dual Cre-mediated and Flp-mediated fluorescent labeling of mutant $\operatorname{Drd} 2^{\text {Pet1-CKO }}$ cells. While complex genetics, this strategy would enable mutant cell visualization for electrophysiology, single-cell RNA sequencing, and analysis of axonal projections.

In both males and females, Drd2-Pet1 neurons densely innervate auditory brainstem regions, likely modulating auditory-related processes at one or multiple of these sites. In examining Drd2-Pet1 efferents, we observed interanimal variability in regional innervation density. We speculate this may arise from subgroups within the Drd2Pet1 neuron population that target different downstream structures. For example, some Drd2-Pet1 neurons may project specifically to the SOC while others might project specifically to the LL. If some animals have more of one subgroup than the other, averaging absolute innervation densities for each target region across all males and females may hide meaningful circuit structure. Covariance analysis of projection targets in each animal thus might hint at which brain regions come under shared regulation by Drd2-Pet1 neurons. In males, the high correlation between auditory region efferent densities suggests shared input from the same Drd2-Pet1 neurons. In females, the $\mathrm{CNC} / \mathrm{SOC}, \mathrm{CNC} / \mathrm{IC}$, SOC/PNC, LL/PNC, and IC/PNC combinations were more negatively correlated, suggesting there might exist a subgroup of Drd2-Pet1 neurons that targets the PNC and a different subgroup, the SOC. We speculate that in males, Drd2-Pet1 neurons contribute to a general level of serotonergic tone across the auditory brainstem, while in females, certain Drd2-Pet1 neurons selectively target and modulate specific nuclei.

In conclusion, we found that $\mathrm{Drd} 2 \mathrm{gene}$ expression in a specialized subset of Pet1 serotonergic neurons is required for certain defensive, dominance, and protective behaviors, involving auditory processing in a sex-specific manner. Deficits in sensory processing such as altered acoustic startle and impaired social communication and dominance behaviors manifest in human disorders including autism spectrum disorder, schizophrenia, and posttraumatic stress disorder, often in sex-specific ways (King et al., 2013; Steel et al., 2014; Matsuo et al., 2016; Thye et al., 2018) and with sex-specific differences in therapeutic outcomes (Franconi et al., 2007). The presented findings, thus, may point to novel circuit nodes of relevance to human neuropsychiatric disease.

\section{References}

Baik JH, Picetti R, Saiardi A, Thiriet G, Dierich A, Depaulis A, Le Meur $M$, Borrelli E (1995) Parkinsonian-like locomotor impairment in mice lacking dopamine D2 receptors. Nature 377:424-428.

Bello EP, Mateo Y, Gelman DM, Noaín D, Shin JH, Low MJ, Alvarez VA, Lovinger DM, Rubinstein M (2011) Cocaine supersensitivity and enhanced motivation for reward in mice lacking dopamine D2 autoreceptors. Nat Neurosci 14:1033-1038.

Brown GL, Ebert MH, Goyer PF, Jimerson DC, Klein WJ, Bunney WE, Goodwin FK (1982) Aggression, suicide, and serotonin: relationships to CSF amine metabolites. Am J Psychiatry 139:741746.

Brust RD, Corcoran AE, Richerson GB, Nattie E, Dymecki SM (2014) Functional and developmental identification of a molecular subtype of brain serotonergic neuron specialized to regulate breathing dynamics. Cell Rep 9:2152-2165.

Calizo LH, Akanwa A, Ma X, Pan YZ, Lemos JC, Craige C, Heemstra LA, Beck SG (2011) Raphe serotonin neurons are not homogenous: electrophysiological, morphological and neurochemical evidence. Neuropharmacology 61:524-543.

Cho JR, Treweek JB, Robinson JE, Xiao C, Bremner LR, Greenbaum A, Gradinaru V (2017) Dorsal raphe dopamine neurons modulate arousal and promote wakefulness by salient stimuli. Neuron 94:1205-1219.e8.

Crawford LK, Rahman SF, Beck SG (2013) Social stress alters inhibitory synaptic input to distinct subpopulations of raphe serotonin neurons. ACS Chem Neurosci 4:200-209.

Davis M, Aghajanian GK (1976) Effects of apomorphine and haloperidol on the acoustic startle response in rats. Psychopharmacology (Berl) 47:217-223.

Davis M, Strachan DI, Kass E (1980) Excitatory and inhibitory effects of serotonin on sensorimotor reactivity measured with acoustic startle. Science 209:521-523.

Davis M, Gendelman DS, Tischler MD, Gendelman PM (1982) A primary acoustic startle circuit: lesion and stimulation studies. J Neurosci 2:791-805.

Deneris E, Gaspar P (2018) Serotonin neuron development: shaping molecular and structural identities. Wiley Interdiscip Rev Dev Biol 7:10.1002.

Franconi F, Brunelleschi S, Steardo L, Cuomo V (2007) Gender differences in drug responses. Pharmacol Res 55:81-95.

Franklin KBJ, Paxinos G (2008) The mouse brain in stereotaxic coordinates, Vol 3. New York: Elsevier.

Gainetdinov RR, Wetsel WC, Jones SR, Levin ED, Jaber M, Caron MG (1999) Role of serotonin in the paradoxical calming effect of psychostimulants on hyperactivity. Science 283:397-401.

Galliciotti G, Sonderegger P (2006) Neuroserpin. Front Biosci 11:3345.

Geyer MA, Braff DL (1987) Startle habituation and sensorimotor gating in schizophrenia and related animal models. Schizophr Bull 13:643-668.

Gong S, Doughty M, Harbaugh CR, Cummins A, Hatten ME, Heintz N, Gerfen CR (2007) Targeting Cre recombinase to specific neuron populations with bacterial artificial chromosome constructs. J Neurosci 27:9817-9823.

Grace AA (2016) Dysregulation of the dopamine system in the pathophysiology of schizophrenia and depression. Nat Rev Neurosci 17:524-532.

Hendricks TJ, Fyodorov DV, Wegman LJ, Lelutiu NB, Pehek EA, Yamamoto B, Silver J, Weeber EJ, Sweatt JD, Deneris ES (2003) Pet-1 ETS gene plays a critical role in 5-HT neuron development and is required for normal anxiety-like and aggressive behavior. Neuron 37:233-247.

Holmes A, Yang RJ, Lesch KP, Crawley JN, Murphy DL (2003) Mice lacking the serotonin transporter exhibit 5-HT(1A) receptor-mediated abnormalities in tests for anxiety-like behavior. Neuropsychopharmacol 28:2077-2088.

Holschbach MA, Vitale EM, Lonstein JS (2018) Serotonin-specific lesions of the dorsal raphe disrupt maternal aggression and caregiving in postpartum rats. Behav Brain Res 348:53-64.

Huang KW, Ochandarena NE, Philson AC, Hyun M, Birnbaum JE, Cicconet M, Sabatini BL (2019) Molecular and anatomical organization of the dorsal raphe nucleus. Elife 8:e46464.

Jensen $P$, Farago AF, Awatramani RB, Scott MM, Deneris ES, Dymecki SM (2008) Redefining the serotonergic system by genetic lineage. Nat Neurosci 11:417-419.

Kane KL, Longo-Guess CM, Gagnon LH, Ding D, Salvi RJ, Johnson KR (2012) Genetic background effects on age-related hearing loss associated with Cdh23 variants in mice. Hear Res 283:80-88.

Kapoor V, Provost AC, Agarwal P, Murthy VN (2016) Activation of raphe nuclei triggers rapid and distinct effects on parallel olfactory bulb output channels. Nat Neurosci 19:271-282. 
Kim JC, Cook MN, Carey MR, Shen C, Regehr WG, Dymecki SM (2009) Linking genetically defined neurons to behavior through a broadly applicable silencing allele. Neuron 63:305-315.

King MW, Street AE, Gradus JL, Vogt DS, Resick PA (2013) Gender differences in posttraumatic stress symptoms among OEF/OIF veterans: an item response theory analysis. J Trauma Stress 26:175-183.

Koch M, Lingenhöhl K, Pilz PK (1992) Loss of the acoustic startle response following neurotoxic lesions of the caudal pontine reticular formation: possible role of giant neurons. Neuroscience 49:617625.

Lammel S, Lim BK, Malenka RC (2014) Reward and aversion in a heterogeneous midbrain dopamine system. Neuropharmacology 76 [Pt B]:351-359.

Lauer AM, Behrens D, Klump G (2017) Acoustic startle modification as a tool for evaluating auditory function of the mouse: progress, pitfalls, and potential. Neurosci Biobehav Rev 77:194-208.

Lindzey G, Winston H, Manosevitz M (1961) Social dominance in inbred mouse strains. Nature 191:474-476.

Liu Z, Zhou J, Li Y, Hu F, Lu Y, Ma M, Feng Q, Zhang JE, Wang D, Zeng J, Bao J, Kim JY, Chen ZF, El Mestikawy S, Luo M (2014) Dorsal raphe neurons signal reward through $5-\mathrm{HT}$ and glutamate. Neuron 81:1360-1374.

Lonstein JS, Gammie SC (2002) Sensory, hormonal, and neural control of maternal aggression in laboratory rodents. Neurosci Biobehav Rev 26:869-888.

Lucki I (1998) The spectrum of behaviors influenced by serotonin. Biol Psychiatry 44:151-162.

Maison SF, Usubuchi H, Liberman MC (2013) Efferent feedback minimizes cochlear neuropathy from moderate noise exposure. $J$ Neurosci 33:5542-5552.

Marr D, Hildreth E (1980) Theory of edge detection. Proc R Soc Lond B Biol Sci 207:187-217.

Matsuo J, Ota M, Hori H, Hidese S, Teraishi T, Ishida I, Hiraishi M, Kunugi $\mathrm{H}$ (2016) A large single ethnicity study of prepulse inhibition in schizophrenia: separate analysis by sex focusing on effect of symptoms. J Psychiatr Res 82:155-162.

McQuin C, Goodman A, Chernyshev V, Kamentsky L, Cimini BA, Karhohs KW, Doan M, Ding L, Rafelski SM, Thirstrup D, Wiegraebe W, Singh S, Becker T, Caicedo JC, Carpenter AE (2018) CellProfiler 3.0: next-generation image processing for biology. PLoS Biol 16:e2005970.

Meincke U, Light GA, Geyer MA, Braff DL, Gouzoulis-Mayfrank E (2004) Sensitization and habituation of the acoustic startle reflex in patients with schizophrenia. Psychiatry Res 126:51-61.

Meloni EG, Davis M (1999) Enhancement of the acoustic startle response in rats by the dopamine D1 receptor agonist SKF 82958. Psychopharmacology (Berl) 144:373-380.

Meloni EG, Davis M (2000a) Enhancement of the acoustic startle response by dopamine agonists after 6-hydroxydopamine lesions of the substantia nigra pars compacta: corresponding changes in c-Fos expression in the caudate-putamen. Brain Res 879:93-104.

Meloni EG, Davis M (2000b) Synergistic enhancement of the acoustic startle reflex by dopamine D1 and 5-HT1A agonists and corresponding changes in c-Fos expression in the dorsal raphe of rats. Psychopharmacology (Berl) 151:359-367.

Moy SS, Nadler JJ, Perez A, Barbaro RP, Johns JM, Magnuson TR, Piven J, Crawley JN (2004) Sociability and preference for social novelty in five inbred strains: an approach to assess autistic-like behavior in mice. Genes Brain Behav 3:287-302.

Nanopoulos D, Belin MF, Maitre M, Vincendon G, Pujol JF (1982) Immunocytochemical evidence for the existence of GABAergic neurons in the nucleus raphe dorsalis. Possible existence of neurons containing serotonin and GABA. Brain Res 232:375-389.

Netser S, Haskal S, Magalnik H, Wagner S (2017) A novel system for tracking social preference dynamics in mice reveals sex- and strain-specific characteristics. Mol Autism 8:53.

Niederkofler V, Asher TE, Okaty BW, Rood BD, Narayan A, Hwa LS, Beck SG, Miczek KA, Dymecki SM (2016) Identification of serotonergic neuronal modules that affect aggressive behavior. Cell Rep 17:1934-1949.

Okaty BW, Freret ME, Rood BD, Brust RD, Hennessy ML, deBairos D, Kim JC, Cook MN, Dymecki SM (2015) Multi-scale molecular deconstruction of the serotonin. Neuron 88:774-791.

Okaty BW, Sturrock N, Escobedo Lozoya Y, Chang Y, Senft RA, Lyon KA, Alekseyenko OV, Dymecki SM (2020) A single-cell transcriptomic and anatomic atlas of mouse dorsal raphe Pet1 neurons. Elife 9:e55523.

Palanza P (2001) Animal models of anxiety and depression: how are females different? Neurosci Biobehav Rev 25:219-233.

Perronnet C, Vaillend C (2010) Dystrophins, utrophins, and associated scaffolding complexes: role in mammalian brain and implications for therapeutic strategies. J Biomed Biotechnol 2010:849426.

Pettersson R, Hagsäter SM, Eriksson E (2016) Serotonin depletion eliminates sex differences with respect to context-conditioned immobility in rat. Psychopharmacology (Berl) 233:1513-1521.

Poulin JF, Caronia G, Hofer C, Cui Q, Helm B, Ramakrishnan C, Chan CS, Dombeck DA, Deisseroth K, Awatramani R (2018) Mapping projections of molecularly defined dopamine neuron subtypes using intersectional genetic approaches. Nat Neurosci 21:1260-1271.

Poulin JF, Gaertner Z, Moreno-Ramos OA, Awatramani R (2020) Classification of midbrain dopamine neurons using single-cell gene expression profiling approaches. Trends Neurosci 43:155169.

Ralph RJ, Paulus MP, Fumagalli F, Caron MG, Geyer MA (2001) Prepulse inhibition deficits and perseverative motor patterns in dopamine transporter knock-out mice: differential effects of D1 and D2 receptor antagonists. J Neurosci 21:305-313.

Ren J, Isakova A, Friedmann D, Zeng J, Grutzner SM, Pun A, Zhao GQ, Kolluru SS, Wang R, Lin R, Li P, Li A, Raymond JL, Luo Q, Luo M, Quake SR, Luo L (2019) Single-cell transcriptomes and wholebrain projections of serotonin neurons in the mouse dorsal and median raphe nuclei. Elife 8:e49424.

Rood BD, Calizo LH, Piel D, Spangler ZP, Campbell K, Beck SG (2014) Dorsal raphe serotonin neurons in mice: immature hyperexcitability transitions to adult state during first three postnatal weeks suggesting sensitive period for environmental perturbation. J Neurosci 34:4809-4821.

Schindelin J, Arganda-Carreras I, Frise E, Kaynig V, Longair M, Pietzsch T, Preibisch S, Rueden C, Saalfeld S, Schmid B, Tinevez JY, White DJ, Hartenstein V, Eliceiri K, Tomancak P, Cardona A (2012) Fiji: an open-source platform for biological-image analysis. Nat Methods 9:676-682.

Scott MM, Wylie CJ, Lerch JK, Murphy R, Lobur K, Herlitze S, Jiang W, Conlon RA, Strowbridge BW, Deneris ES (2005) A genetic approach to access serotonin neurons for in vivo and in vitro studies. Proc Natl Acad Sci USA 102:16472-16477.

Sengupta A, Bocchio M, Bannerman DM, Sharp T, Capogna M (2017) Control of amygdala circuits by 5-HT neurons via 5-HT and glutamate cotransmission. J Neurosci 37:1785-1796.

Seo C, Guru A, Jin M, Ito B, Sleezer BJ, Ho YY, Wang E, Boada C, Krupa NA, Kullakanda DS, Shen CX, Warden MR (2019) Intense threat switches dorsal raphe serotonin neurons to a paradoxical operational mode. Science 363:538-542.

Shikanai H, Yoshida T, Konno K, Yamasaki M, Izumi T, Ohmura Y, Watanabe M, Yoshioka M (2012) Distinct neurochemical and functional properties of GAD67-containing 5-HT neurons in the rat dorsal raphe nucleus. J Neurosci 32:14415-14426.

Shioda N, Imai Y, Yabuki Y, Sugimoto W, Yamaguchi K, Wang Y, Hikida T, Sasaoka T, Mieda M, Fukunaga K (2019) Dopamine $D_{2 L}$ receptor deficiency causes stress vulnerability through $5-\mathrm{HT}_{1 \mathrm{~A}}$ receptor dysfunction in serotonergic neurons. J Neurosci 39:75517563.

Shrestha BR, Chia C, Wu L, Kujawa SG, Liberman MC, Goodrich LV (2018) Sensory neuron diversity in the inner ear is shaped by activity. Cell 174:1229-1246.e17. 
Spaethling JM, Piel D, Dueck H, Buckley PT, Morris JF, Fisher SA, Lee J, Sul JY, Kim J, Bartfai T, Beck SG, Eberwine JH (2014) Serotonergic neuron regulation informed by in vivo single-cell transcriptomics. FASEB J 28:771-780.

Spannuth BM, Hale MW, Evans AK, Lukkes JL, Campeau S, Lowry CA (2011) Investigation of a central nucleus of the amygdala/dorsal raphe nucleus serotonergic circuit implicated in fear-potentiated startle. Neuroscience 179:104-119.

Steel Z, Marnane C, Iranpour C, Chey T, Jackson JW, Patel V, Silove D (2014) The global prevalence of common mental disorders: a systematic review and meta-analysis 1980-2013. Int J Epidemiol 43:476-493.

Takahashi H, Kamio Y (2018) Acoustic startle response and its modulation in schizophrenia and autism spectrum disorder in Asian subjects. Schizophr Res 198:16-20.

Tammimäki A, Käenmäki $M$, Kambur $\mathrm{O}$, Kulesskaya N, Keisala T, Karvonen E, García-Horsman JA, Rauvala H, Männistö PT (2010) Effect of S-COMT deficiency on behavior and extracellular brain dopamine concentrations in mice. Psychopharmacology (Berl) 211:389-401.

Terranova JI, Song Z, Larkin TE 2nd, Hardcastle N, Norvelle A, Riaz A, Albers HE (2016) Serotonin and arginine-vasopressin mediate sex differences in the regulation of dominance and aggression by the social brain. Proc Natl Acad Sci USA 113:13233-13238.

Thye MD, Bednarz HM, Herringshaw AJ, Sartin EB, Kana RK (2018) The impact of atypical sensory processing on social impairments in autism spectrum disorder. Dev Cogn Neurosci 29:151-167.
Tischler MD, Davis M (1983) A visual pathway that mediates fearconditioned enhancement of acoustic startle. Brain Res 276:55-71.

van den Berg WE, Lamballais S, Kushner SA (2015) Sex-specific mechanism of social hierarchy in mice. Neuropsychopharmacology 40:13641372.

Wang HL, Zhang S, Qi J, Wang H, Cachope R, Mejias-Aponte CA, Gomez JA, Mateo-Semidey GE, Beaudoin GMJ, Paladini CA, Cheer JF, Morales M (2019) Dorsal raphe dual serotonin-glutamate neurons drive reward by establishing excitatory synapses on VTA mesoaccumbens dopamine neurons. Cell Rep 26:1128-1142.e7.

Weissbourd B, Ren J, DeLoach KE, Guenthner CJ, Miyamichi K, Luo $L$ (2014) Presynaptic partners of dorsal raphe serotonergic and GABAergic neurons. Neuron 83:645-662.

Yu Q, Teixeira CM, Mahadevia D, Huang Y, Balsam D, Mann JJ, Gingrich JA, Ansorge MS (2014) Dopamine and serotonin signaling during two sensitive developmental periods differentially impact adult aggressive and affective behaviors in mice. Mol Psychiatry 19:688-698.

Zhou T, Zhu H, Fan Z, Wang F, Chen Y, Liang H, Yang Z, Zhang L, Lin L, Zhan Y, Wang Z, Hu H (2017) History of winning remodels thalamo-PFC circuit to reinforce social dominance. Science 357:162-168.

Zhou X, Jen PH, Seburn KL, Frankel WN, Zheng QY (2006) Auditory brainstem responses in 10 inbred strains of mice. Brain Res 1091:16-26. 